\title{
LA DOCENCIA DE LA CONSTITUCIÓN FEDERAL EN EL CONTEXTO DE LA BACHILLERATO INTEGRADO DEL INSTITUTO FEDERAL DE EDUCACIÓN, CIENCIA Y TECNOLOGÍA DE AMAPÁ (IFAP)
}

\section{ARTÍCULO ORIGINAL}

COSTA, Pedro Henrique Maia1 ${ }^{1}$, COSTA, Susane de Almeida Aranha², FECURY, Amanda Alves ${ }^{3}$, DENDASCK, Carla Viana ${ }^{4}$, OLIVEIRA, Euzébio de ${ }^{5}$, DIAS, Claudio Alberto Gellis de Mattos ${ }^{6}$

COSTA, Pedro Henrique Maia. Et al. La Docencia de la Constitución Federal en el contexto de la Bachillerato Integrado del Instituto Federal de Educación, Ciencia y Tecnología de Amapá (IFAP). Revista Científica Multidisciplinar Núcleo do Conhecimento. Año 06, Ed. 04, Vol. 10, pp. 123-139. Abril de 2021. ISSN: 24480959, Enlace de acceso: https://www.nucleodoconhecimento.com.br/educaciones/integrado-del-instituto, DOI: 10.32749/nucleodoconhecimento.com.br/educaciones/integrado-del-instituto

\section{RESUMEN}

Nuestra Constitución Federal de 1988 colocó a la Educación como un derecho fundamental en la lista de derechos sociales. Uno de los propósitos de la Educación

\footnotetext{
${ }^{1}$ Ingeniero Civil, Profesor e investigador del Instituto de Educación Básica, Técnica y Tecnológica de Amapá (IFAP), estudiante del Programa de Posgrado Lato Sensu en Educación Profesional (IFAP).

${ }^{2}$ Abogado, Catedrático de Letras, Postgrado en Metodología de la Enseñanza del Idioma Inglés (UNITER) y Derecho Civil y Empresarial (DAMASO).

${ }^{3}$ Biomédico, Doctor en Enfermedades Trópicas, Profesor e investigador del Curso Médico del Campus Macapá, Universidad Federal de Amapá (UNIFAP).

${ }^{4}$ Teóloga, Doctora en Psicoanálisis Clínica. Ha trabajado durante 15 años con Metodología Científica (Método de Investigación) en la Orientación de Producción Científica de estudiantes de Maestría y Doctorado. Especialista en Investigación e Investigación de Mercados con foco en el área de la Salud.

${ }^{5}$ Biólogo, Doctor en Enfermedades Trópicas, Profesor e investigador del Curso de Educación Física de la Universidad Federal de Pará (UFPA).

${ }^{6}$ Biólogo, Doctor en Teoría e Investigación del Comportamiento, Profesor e investigador del Curso de Grado de Química del Instituto de Educación Básica, Técnica y Tecnológica de Amapá (IFAP) y del Programa de Posgrado en Educación Profesional y Tecnológica (PROFEPT IFAP).
}

RC: 83560

Disponível em: https://www.nucleodoconhecimento.com.br/educacion-es/integradodel-instituto 
es asegurar y preparar al estudiante para el ejercicio del ciudadano. Las propuestas destacadas no tienen el propósito de formar una licenciatura en derecho, sino más bien un ciudadano consciente, que reconozca sus derechos y deberes básicos ante la sociedad y el Estado. El objetivo de esta investigación es verificar la posibilidad real de introducir el estudio de la Constitución Federal (CF) en el IFAP, basado en el conocimiento de estos estudiantes sobre los entendimientos básicos sobre la Constitución Federal. Los cuestionarios estructurados se utilizaron con preguntas cerradas y abiertas, de carácter disertación y otros de carácter objetivo, aplicados en enero de 2018 a los participantes implicados, con la ayuda de Google Forms. La Preparatoria Brasileña, examinada a partir de un corte puntual en el curso técnico en edificios en forma integralizada del IFAP, campus Macapá, no puede cumplir con las recomendaciones del CF y el LDB de acuerdo con el resultado del cuestionario aplicado a los estudiantes. Esta enseñanza ocupa un lugar privilegiado en la formación educativa brasileña, entre lo elemental y lo superior. Los estudiantes muestran estar entusiasmados con la posibilidad de implementar escaneos básicos en el curso técnico en edificios del IFAP, campus Macapá, aunque opcionalmente.

Palabras clave: EPT, Ley, Educación, Constitución, Bachillerato.

\section{INTRODUCCÍON}

Nuestra Constitución Federal de 1988 situó a la Educación como un derecho fundamental en la lista de derechos sociales, consagrando constitucionalmente su importancia para la formación y la vida en la sociedad. La educación de una población es una condición indispensable para el desarrollo de un Estado ya sea en el ámbito social, cultural, económico y científico (BRASIL, 2012).

La Constitución de la República Federativa de Brasil de 1988 (CFRB/1988) establece, en su artículo 1, que: "la República Federativa de Brasil, formada por la unión indisoluble de estados y municipios y el Distrito Federal, constituye un Estado 
democrático de Derecho y tiene como fundamento: II - ciudadanía;[...]" (BRASIL, 2012).

Según ANTONELLO y NOREMBERG (2016), la ciudadanía es un estatus en el que, si su principal objetivo es lograr la plenitud del ejercicio de los derechos fundamentales inherentes al individuo, un estatus que está intrínsecamente vinculado al régimen político, ya que, será a través de esto que el ciudadano, a través de sus representantes, logrará su derecho a las políticas públicas, es decir, una educación ejemplar, salud, seguridad, entre otros.

La Ley de Directrices y Bases de La Educación Brasileña (LDB 9394/96) es la legislación que regula el sistema educativo (público o privado) del Brasil, desde la educación básica hasta la educación superior. Uno de los propósitos de Educación, es asegurar y preparar al estudiante para el ejercicio del ciudadano, la idea de este artículo es discutir la mejor manera de llegar a este propósito, basando y justificando todas las posiciones tomadas (BRASIL, 2016).

El 16 de febrero de 2017, el actual presidente Michel Temer sancionó la Ley № 13.415 que reforma la escuela secundaria, pero esta reforma dependerá directamente del desarrollo de la nueva Base Curricular Nacional Común (BNCC), que debería ser aprobada a finales de este año 2018. La nueva escuela secundaria fue editada a través de medidas provisionales (MP) estrictamente siguiendo los requisitos previstos en la Constitución Federal, pero algunos expertos consideran que esta forma de acción es un revés social, ya que los cambios deberían haber sido discutidos abiertamente con la sociedad, y no implementados a través del MP (BRASIL, 2017).

La Ley de Directrices y Bases de La Educación Brasileña (LDB 9394/96), en los artículos 2 y 22, establece que la educación tiene como objetivo el pleno desarrollo del estudiante y su preparación para el ejercicio de la ciudadanía, garantizada a través de la educación básica. Pero para lograr este objetivo, es esencial democratizar el conocimiento legal dentro de la sociedad (BRASIL, 2016).

RC: 83560

Disponível em: https://www.nucleodoconhecimento.com.br/educacion-es/integradodel-instituto 
En la búsqueda de este éxito, actualmente, la ley se ha observado con otros ojos, ya no con una visión positivista y restringida, sino ahora como un conocimiento necesario e indispensable para la vida del individuo. Sin embargo, es palpable la ignorancia que una parte significativa del pueblo brasileño presenta en relación con los fundamentos de la Constitución Federal, esta percepción fue confirmada por una investigación datasenate hecha exclusivamente para una edición especial en 2013 (SASSE, 2013)

Según MORAES (2013), "hay numerosas razones para que las materias legales se incluyan en la escuela secundaria. Pero lo básico es formar un ciudadano, individuos que formen opiniones, conocedores de sus derechos y deberes".Sin embargo, si la intención es la adecuada formación de los ciudadanos a través del conocimiento jurídico, es prudente demostrar que, de cierta manera, esta idea ya se está cumpliendo en Brasil, incluso de una manera incipiente y puntual.

El Estatuto del Niño y el Adolescente (ECA) fue establecido por la Ley № 8.069 el 13 de julio de 1990. Regula los derechos y prevé la plena protección de los niños y adolescentes inspirados en los principios constitucionales. Aunque el ECA es una ley vigente desde 1990, ha habido una serie de dificultades y desafíos para su aplicación en la sociedad brasileña. Los principales responsables de la protección y observancia de los derechos de los niños y adolescentes son, además de la sociedad en general, las autoridades familiares y públicas (SARAIVA, 2017).

El Colegio de Abogados de Brasil (OAB) creó un proyecto didáctico para escuelas secundarias en Brasil, llamado OAB va a la escuela que comenzó en 1993 por iniciativa del consejero de OAB SP y presidente de la Comisión de Ciudadanía y Acción Social, en ese momento, Alexandre da Silva Filho, en la ciudad de Osasco, y ampliado por todo Brasil , cubriendo alrededor de 20 millones de alumnos de escuelas públicas. Varias escuelas públicas de Brasil fueron contempladas por el proyecto, con el objetivo de aclarar el papel de la propia OAB en el Estado y su funcionamiento, además de contribuir a la ciudadanía de los estudiantes a través de 
conferencias, folletos, películas educativas $y$, por supuesto, con debates que estimulen su interés por el conocimiento jurídico. (SILVA FILHO, 2004).

DIAS y DE OLIVEIRA (2015) presentan algunas sugerencias sobre los contenidos básicos de la ley que pueden integrarse en la educación regular, a saber, los conceptos de Derechos Humanos, el Estatuto de la infancia y la adolescencia, los derechos de los consumidores, incluso con énfasis en el mercado electrónico, la educación fiscal y también los caminos de la justicia.

MORAES (2013) considera que sería de gran valor social incluir en la preparatoria las siguientes disciplinas: Introducción al Derecho, Derechos y Garantías Constitucionales, Derecho Penal, Derecho Civil y Leyes Escasas, como el estudio de algunas leyes como el Estatuto de la Niñez y la Adolescencia. El estudiante también necesitaría tener conocimientos básicos sobre administración pública, jerarquía de poderes, creación y promulgación de leyes.

Las propuestas destacadas no tienen el propósito de formar una licenciatura en derecho, sino más bien un ciudadano consciente, que reconozca sus derechos y deberes básicos ante la sociedad y el Estado.

\section{GOL}

Verificar la posibilidad real de introducir el estudio de la Constitución Federal (CF) en el IFAP, basado en el conocimiento de estos estudiantes sobre los entendimientos básicos sobre la Constitución Federal.

\section{MÉTODO}

Los cuestionarios estructurados se utilizaron con preguntas cerradas y abiertas, de carácter disertación y otros de carácter objetivo, aplicados en enero de 2018 a los participantes implicados, con la ayuda de Google Forms. 
El público objetivo estaba compuesto por 20 docentes del curso técnico colegiado en edificación en forma integralizada, pedagogos y coordinadores de cursos técnicos en forma integralizada, el director de docencia y el director general del IFAP, campus Macapá, además de algunos abogados pertenecientes a la OAB en el estado de Amapá, empleados del propio IFAP. Otro cuestionario con preguntas cerradas, de carácter objetivo, se aplicó a 106 alumnos de los cursos técnicos de edificios ifap en el campus de Macapá sin previo aviso, divididos en cinco secciones para verificar el grado de conocimiento que presentaron en relación con la visibilidad social de las tres potencias en el ámbito municipal, al hijo básico de la Constitución Federal y en relación con los principios de justicia, derivados de las costumbres y/o sentido común de una sociedad.

\section{RESULTADOS Y DISCUSIÓN}

Tanto el análisis cuantitativo como el cualitativo trataron de agrupar las preguntas por secciones específicas de los puntos a investigar para facilitar la interpretación de los datos y el debate de los resultados.

\section{CUESTIONARIO APLICADO AL PERSONAL TÉCNICO DEL IFAP}

Analizando la figura 01, podemos observar que la mayoría de los participantes de este cuestionario tienen treinta años, la mayoría de los cuales tienen 32 años. Este resultado se debe a que ifap es una institución reciente, donde existe la entrada constante de profesionales para satisfacer la creciente demanda del público objetivo (IFAP, 2021). 
Figura 01 Número entrevistado según la edad.

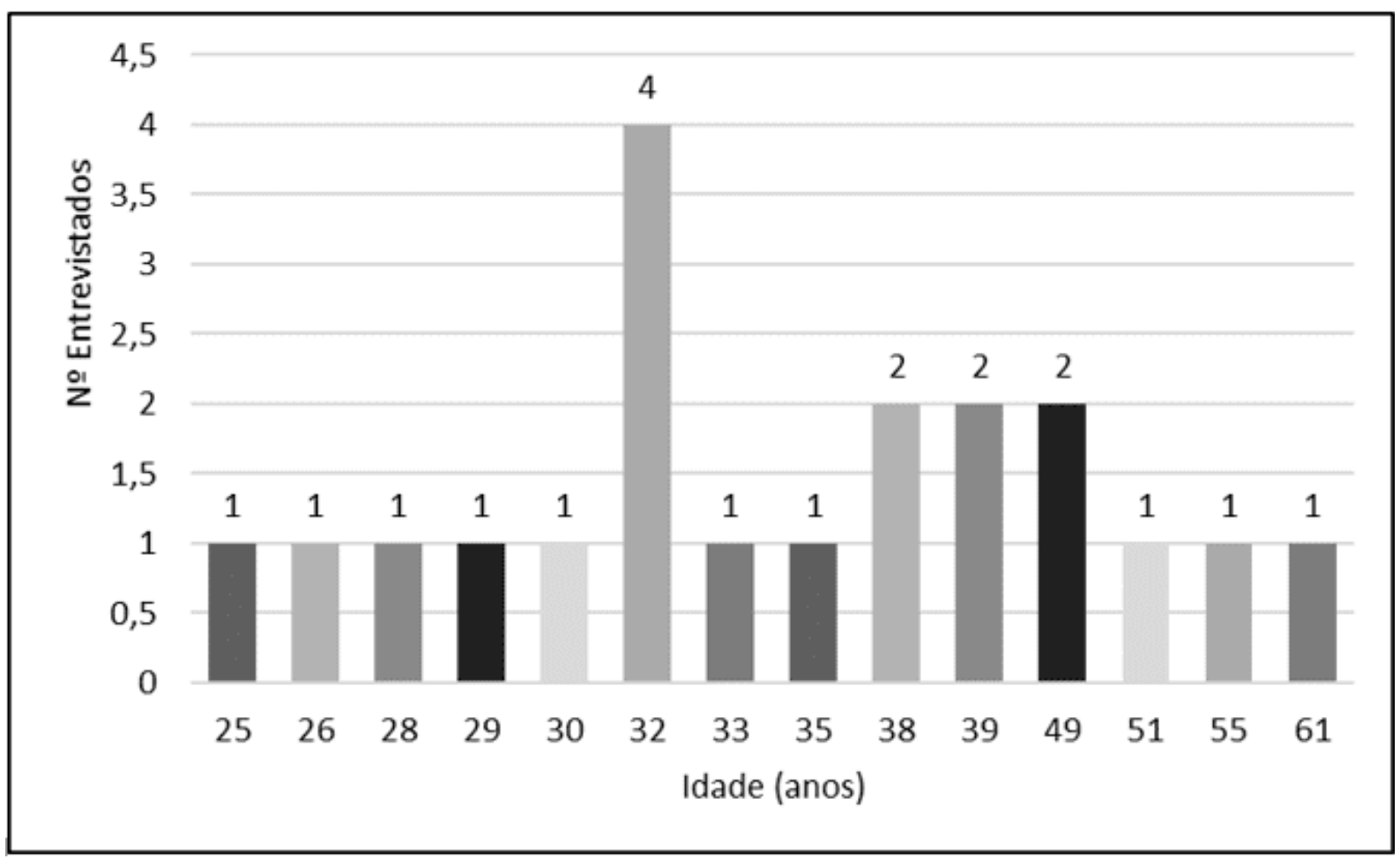

RC: 83560

Disponível em: https://www.nucleodoconhecimento.com.br/educacion-es/integradodel-instituto 
Figura 02: Porcentaje de entrevistados según género.

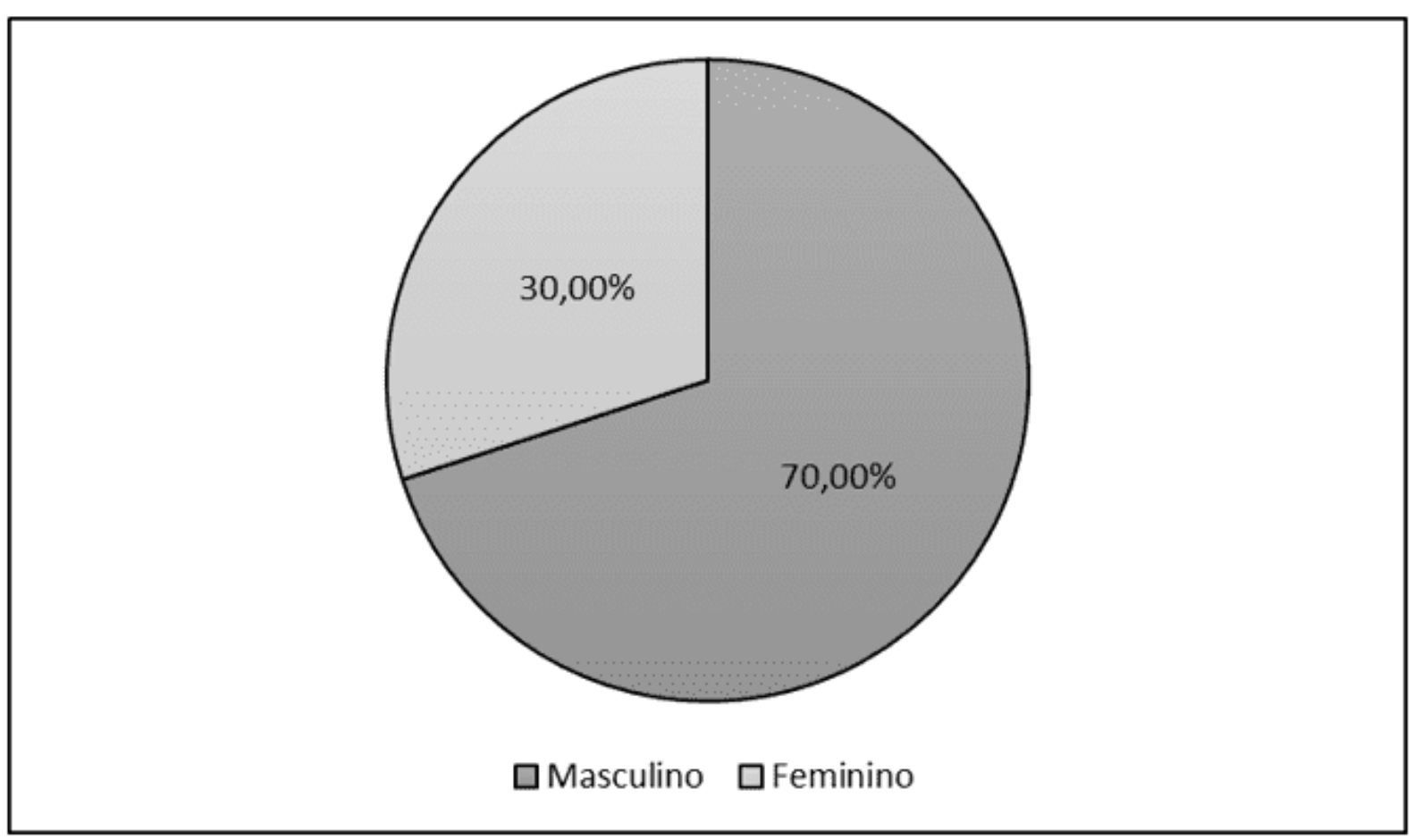

La Figura 02 muestra un mayor número de entrevistados masculinos, más del doble que muchas mujeres, un hecho que no se evidenció en los resultados del cuestionario aplicado a los estudiantes, que demostró una cierta homogeneidad en relación con el género. Esto es un reflejo del mayor número de hombres en el mercado laboral brasileño (NÓBREGA et al., 2019).

En cuanto a la profesión/puesto, la Figura 03 presenta un resultado esperado, en el que el mayor número de encuestados fueron profesores de la base docente nacional común del curso técnico en edificios, ya que las disciplinas del BNCC acumulan aproximadamente el $69 \%$ de la carga de trabajo total del curso (IFAP, 2019). 
Figura 03 Número entrevistado según profesión /posición.

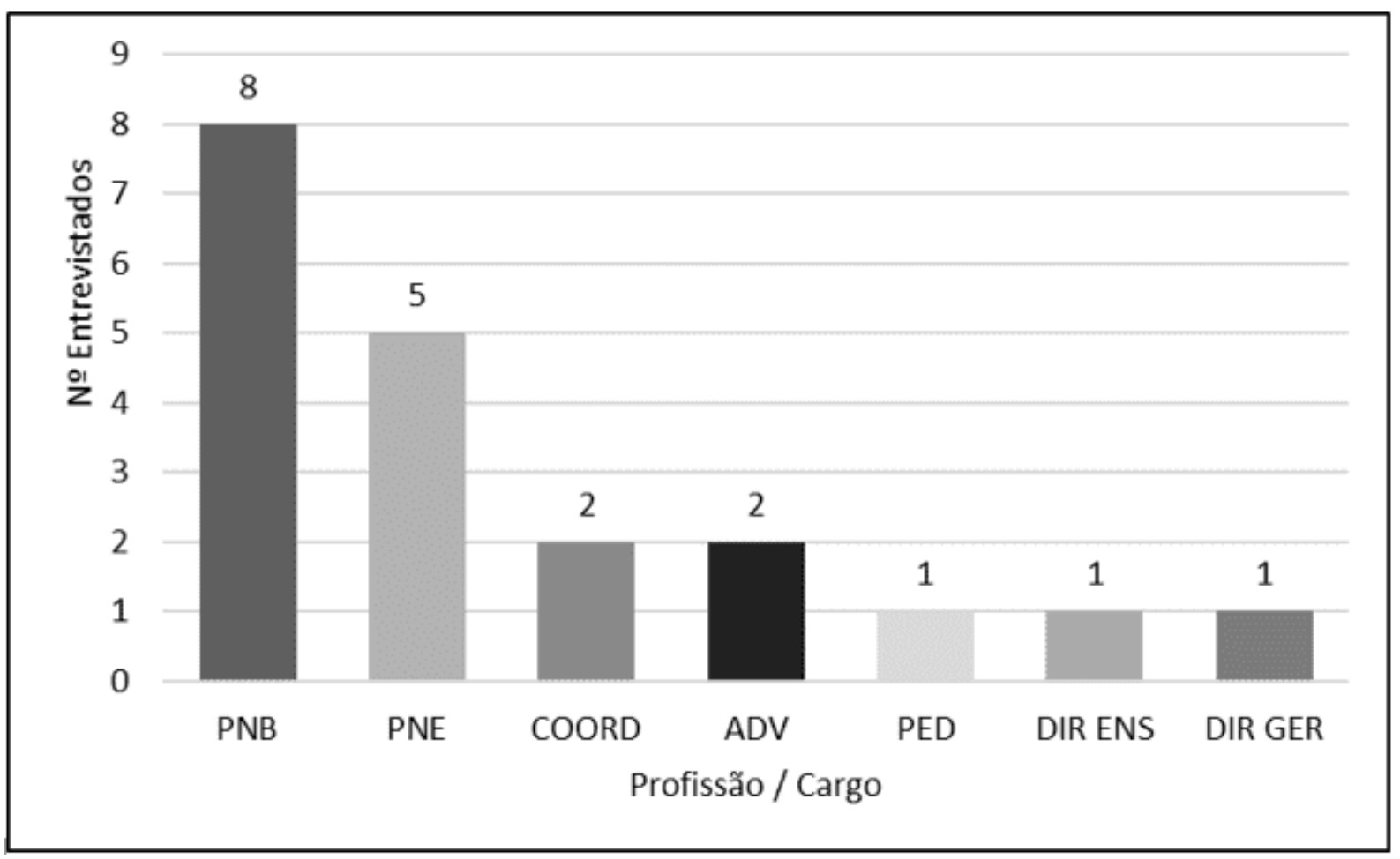

RC: 83560

Disponível em: https://www.nucleodoconhecimento.com.br/educacion-es/integradodel-instituto 
Figura 04 Número entrevistado de acuerdo con el tiempo de experiencia profesional.

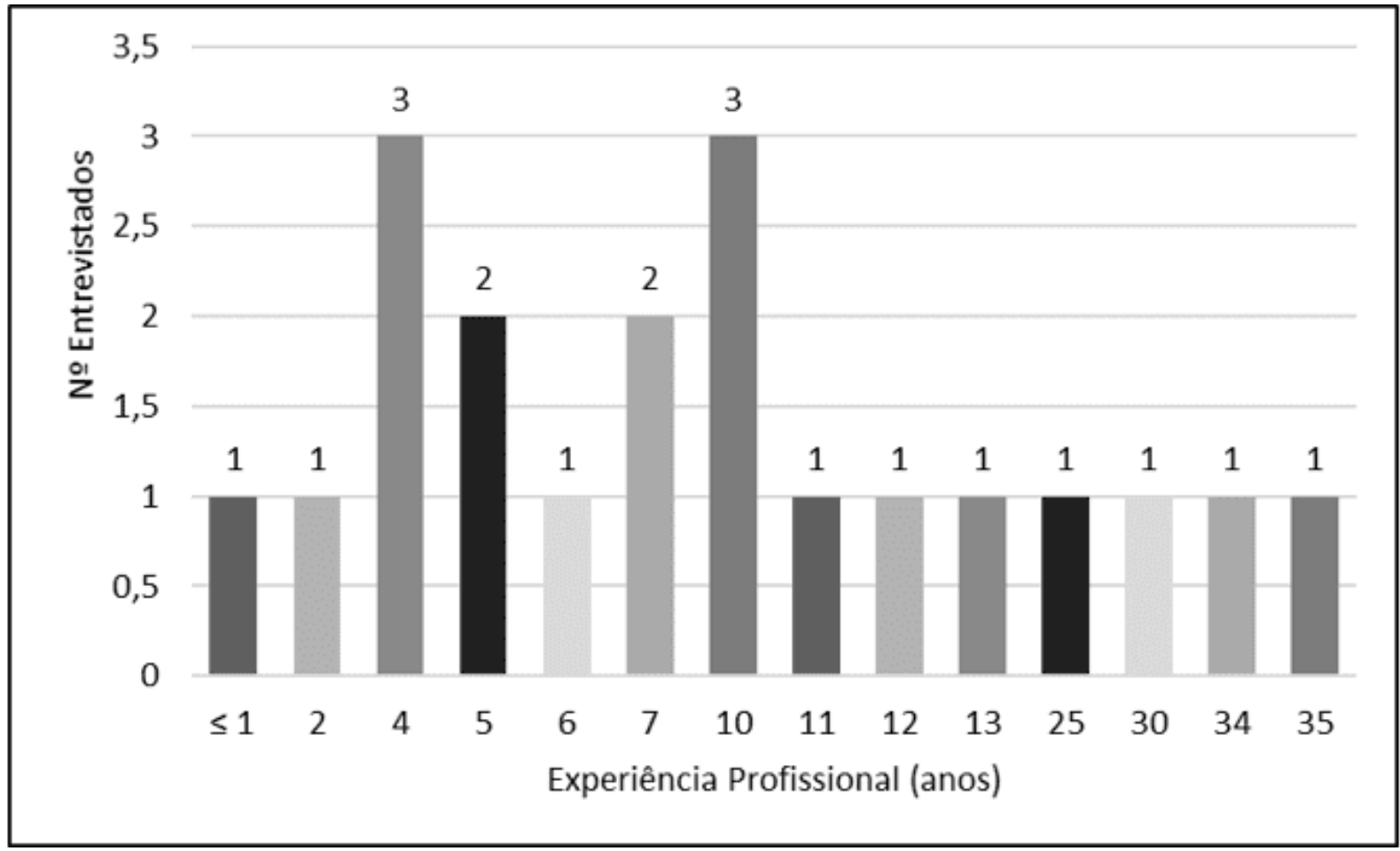

En la figura 04, observamos que la mayoría de los entrevistados no tienen una amplia experiencia profesional, a pesar de que los resultados se consideran muy relevantes, porque todos los entrevistados son empleados públicos que no necesitan omitir o distorsionar las respuestas por razones ajenas (BRASIL, 1990).

Los entrevistados, cuando se les preguntó si ya habían leído o manejado (chapa) el CF, el $90 \%$ respondió positivamente, como se evidencia en la Figura 05 y la mayoría informó que la parte que llamó su atención fueron los "Derechos y Garantías Fundamentales", especialmente el Artículo 5 y el Derecho Social a la Educación, enumerado en el Artículo 6, mostrando que la mayoría de los profesionales acceden a la Carta Magna para conocer sus derechos y garantías y, lógicamente, sobre el área de la educación, ya que la mayoría de los entrevistados son profesores y trabajan en el área de enseñanza (BRASIL, 1990). 
Figura 05 Porcentaje de entrevistados que han leído o manejado (frondo) el CF.

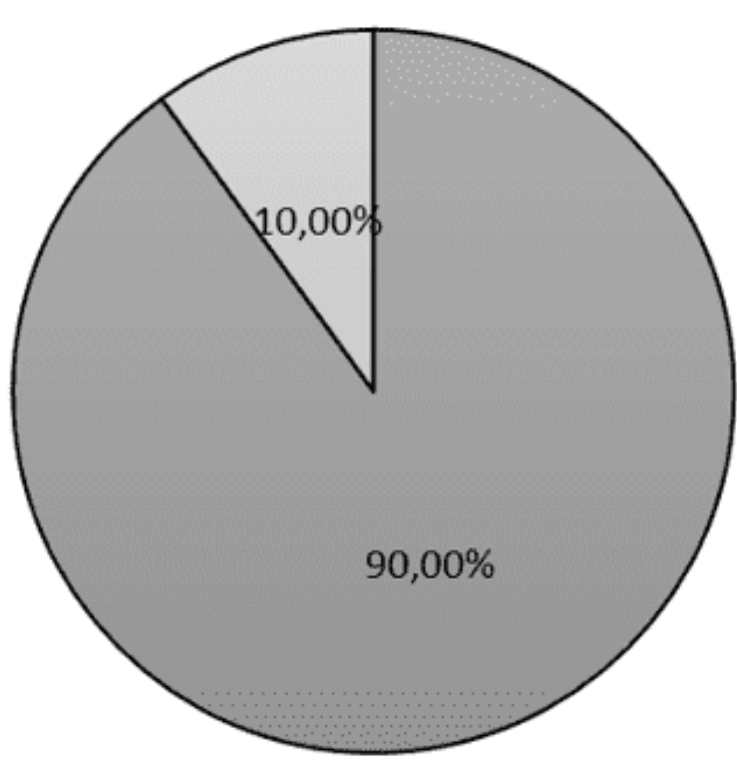

$\square \operatorname{Sim} \square$ Não

En cuanto al grado de conocimiento que los participantes de la entrevista consideran tener en relación con el CF de 1988, el $55 \%$ de ellos considera no tener suficiente conocimiento para el pleno ejercicio de la ciudadanía, el 40\% considera tener suficiente conocimiento y sólo un abogado consideró tener un excelente conocimiento de nuestra Constitución Federal, lo cual era de esperar, porque actúa directamente con el tema solicitado, este resultado puede demostrarse en las cifras 06, lo que demuestra un equilibrio en el grado de conocimiento de los participantes en relación con el CF (FONSECA y FERNANDES, 2020). 
Figura 06 Grado de conocimiento en relación con CF 1988 - A) número de entrevistados; B) porcentaje de encuestados

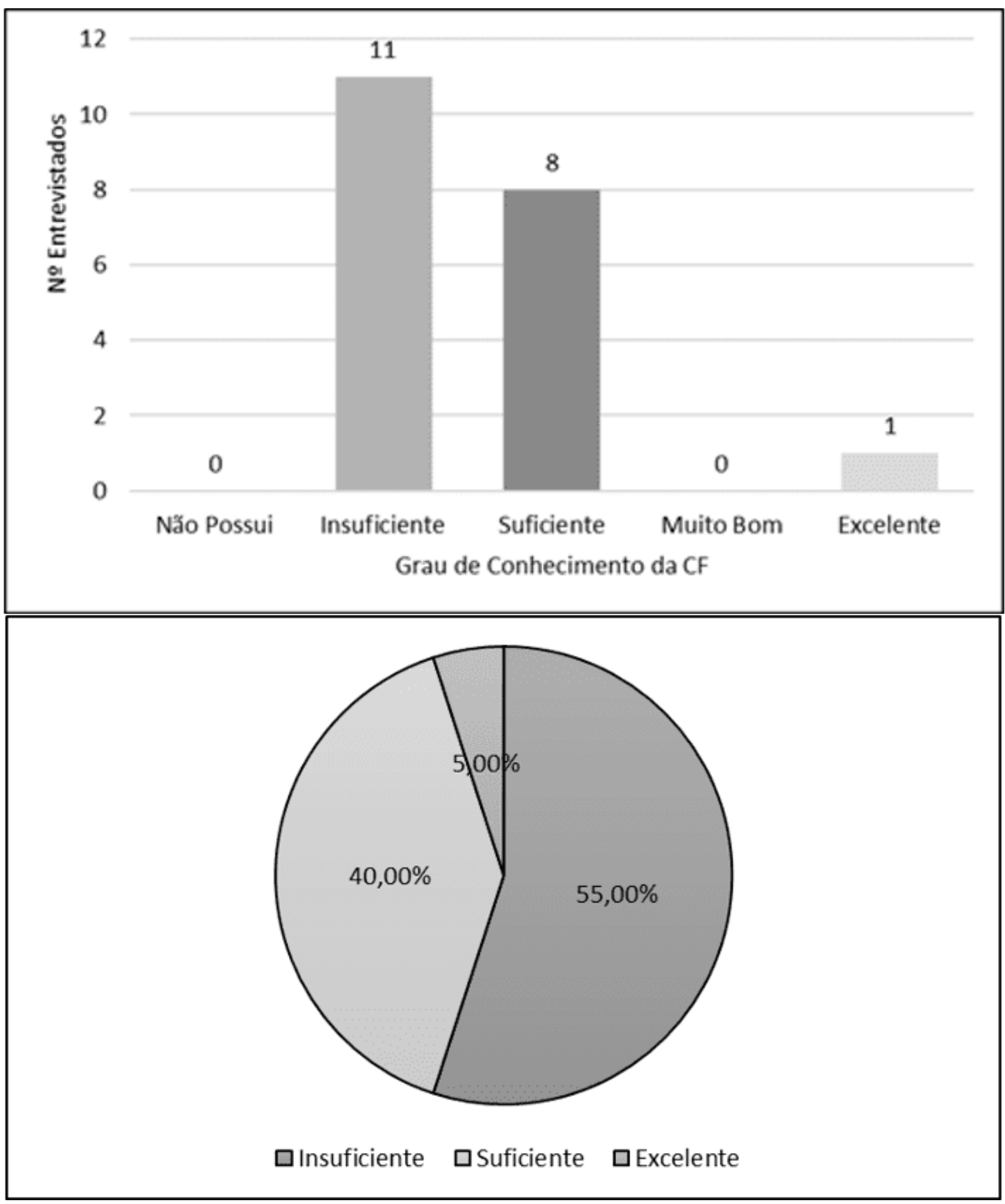

RC: 83560

Disponível em: https://www.nucleodoconhecimento.com.br/educacion-es/integradodel-instituto 
Cuandose le preguntó sobre la pertinencia de la enseñanza básica de la Constitución Federal en la educación básica actual, la gran mayoría consideró esta enseñanza extremadamente importante para los estudiantes, incluso si en su forma básica, contribuyendo al crecimiento intelectual y humanista de los estudiantes (LORENSET et al., 2021).

En cuanto al conocimiento de algún proyecto de ley propuesto en un intento de formalizar la enseñanza del derecho en las escuelas, sólo el 20\% respondió tener conocimiento (figura 07) y citó principalmente el proyecto de ley del senador Romário, aunque superficialmente encontró que este proyecto de ley es el más conocido con la comunidad académica (ROMARIO, 2021).

Figura 07 Porcentaje de encuestados que conocen algún proyecto de ley en un intento de formalizar la enseñanza del derecho en las escuelas.

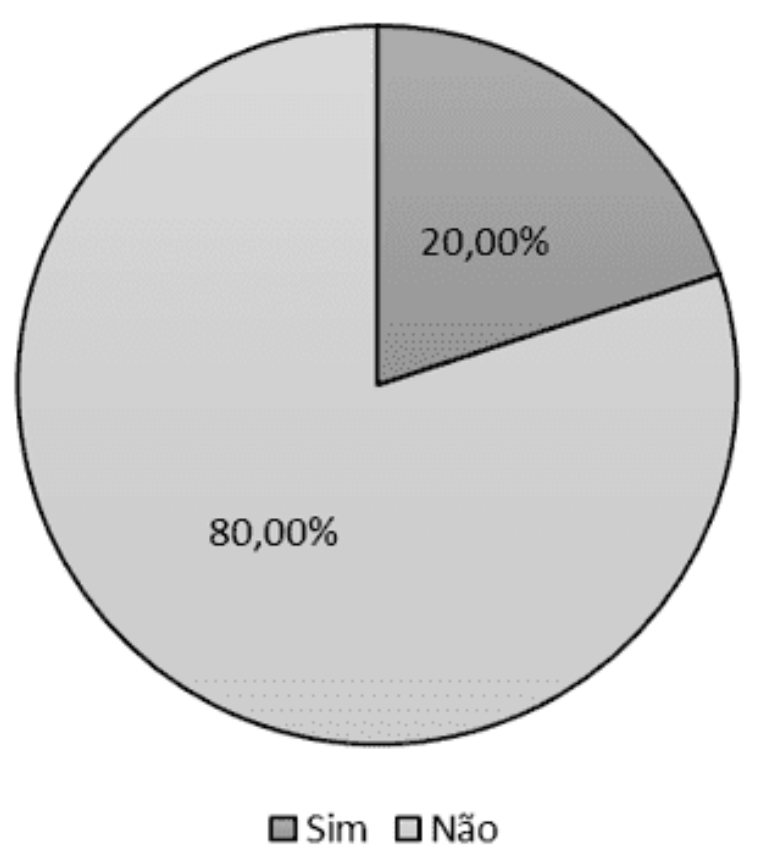

Cuando se les abordó sobre el contenido de las sumas básicas de la Constitución Federal que deben enseñarse a los estudiantes de educación básica, las principales 
materias mencionadas fueron: Derechos y Garantías Fundamentales, Ciudadanía, Principios Fundamentales, Estatuto de la Niñez y adolescencia y derechos humanos. Desde el punto de vista del $40 \%$ de los entrevistados, estos contenidos deben ser estudiados tanto en primaria como en secundaria y, como se muestra en la Figura 08, ningún entrevistado eligió la alternativa de estudiar estos contenidos sólo en la educación superior, lo que ya demuestra una tendencia favorable a implementar esta enseñanza en la educación básica (HOHENDORFF et al., 2020).

Figura 08 Dictamen sobre la etapa en que se debe estudiar la Enseñanza de los Fundamentos del $\mathrm{CF}$ - a) número de entrevistados; b) porcentaje de encuestados.

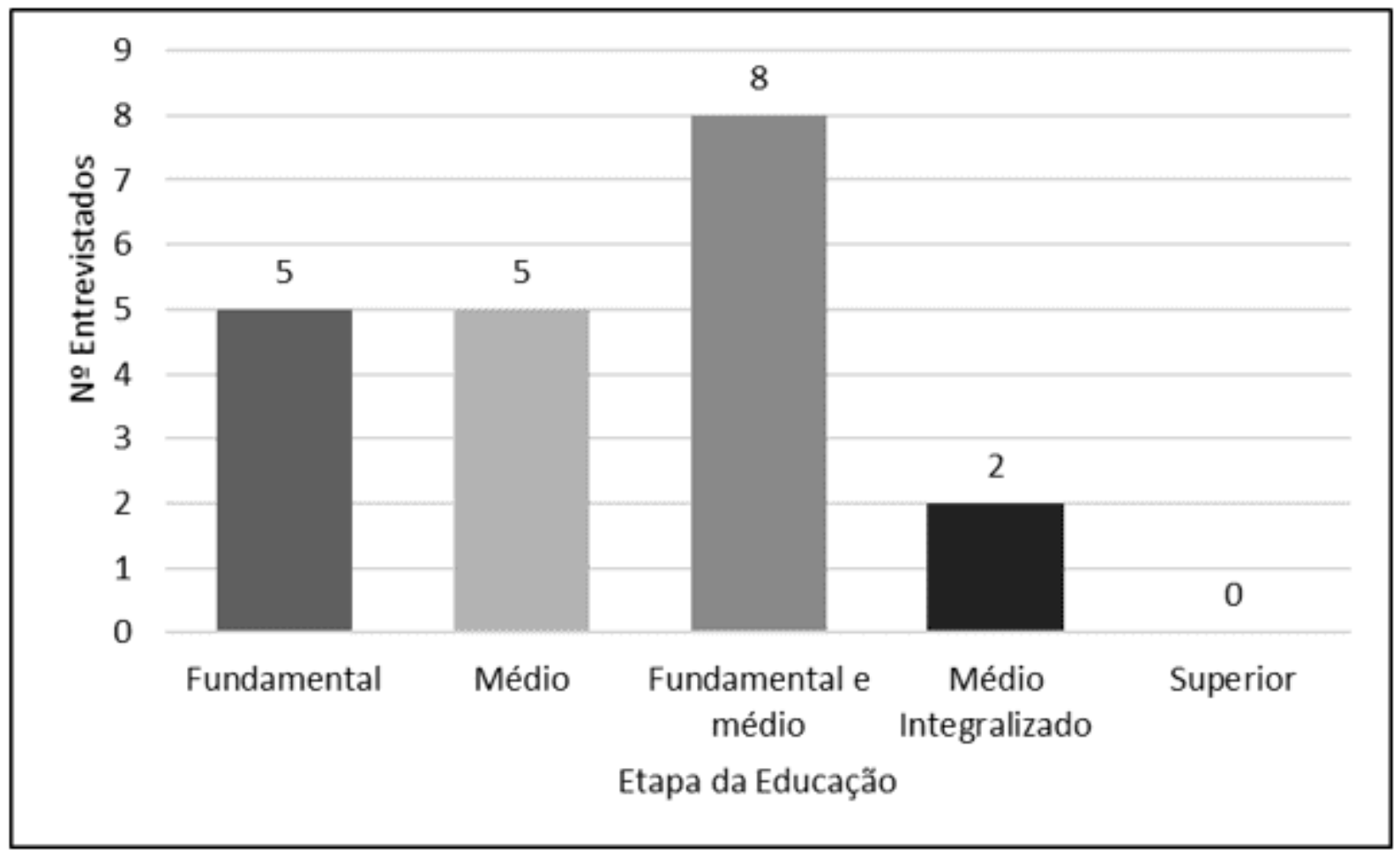

RC: 83560

Disponível em: https://www.nucleodoconhecimento.com.br/educacion-es/integradodel-instituto 


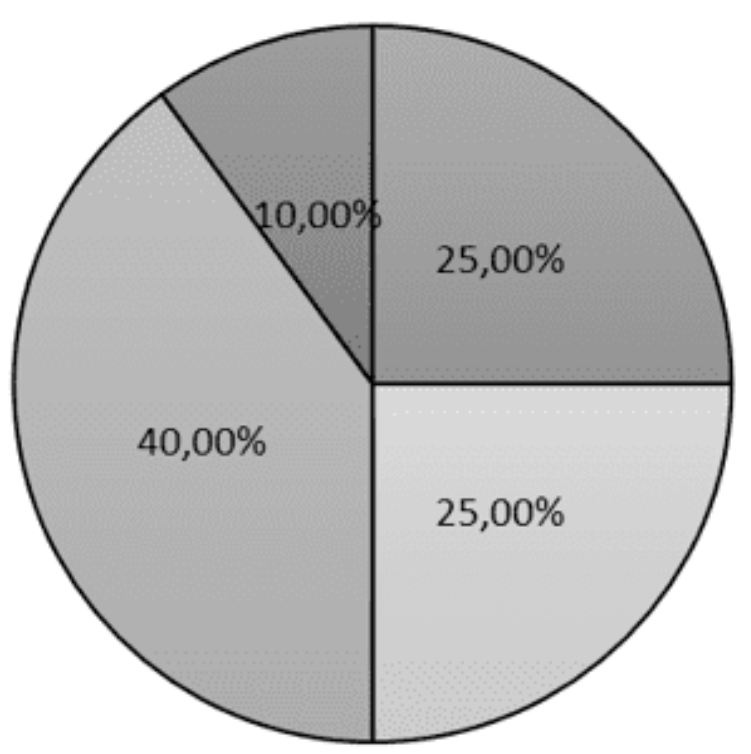

\section{afundamental $\square$ Médio $\square$ Fundamental e médio $\square$ Médio Integralizado}

A los entrevistados se les preguntó si tuvieron la oportunidad a lo largo de su vida académica de estudiar materias como Organización Social y Política de Brasil (OSPB) y Educación Moral y Cívica (EMC), el 55\% de los entrevistados nunca estudió esas materias y el $45 \%$ tuvo la oportunidad de estudiarlas a lo largo de su vida académica. Esto refleja la edad de los entrevistados, ya que los mayores de 35 años probablemente completaron la educación básica en la época del Régimen Militar, período en el que estas materias fueron ampliamente difundidas en la educación básica en las escuelas públicas (AMARAL y CASTRO, 2020). La mayoría de los encuestados que respondieron positivamente a la pregunta argumentaron que estas disciplinas contribuyeron a la formación de un pensamiento más crítico, individuos más conscientes de sus derechos y deberes y más preparados para el ejercicio de la ciudadanía (TAVARES et al., 2020).

De acuerdo con la posibilidad de implementar la enseñanza de sumas básicas de la Constitución Federal en el escenario actual de la educación brasileña, sólo dos entrevistados, un maestro del núcleo común y otro del núcleo específico, se opusieron a esta propuesta, alegando una alta carga de trabajo en la educación 
básica y el hecho de que esta propuesta tenía que partir del Ministerio de Educación (MEC) para ser implementada, de lo contrario sería inviable. Por otro lado, la mayoría de los encuestados se mostró a favor de la propuesta, alegando que los avances tecnológicos facilitarían esta enseñanza, además de promover un cambio gradual en el actual escenario político brasileño y un aumento de la concienciación de los ciudadanos sobre sus derechos y deberes (TAVARES et al., 2020).

\section{CUESTIONARIO APLICADO A ESTUDIANTES DEL CURSO TÉCNICO DEL IFAP}

La Figura 9 muestra que la mayoría de los estudiantes que participaron en la investigación tienen entre 15 y 18 años, esto se debe al hecho de que los entrevistados son estudiantes de secundaria en la forma integralizada que se ajustan a este grupo de edad. También detectamos que la mayoría de los participantes tenían 15 años, este resultado se confirma mediante el gráfico de la Figura 10, que explica que la mayoría de los estudiantes que respondieron al cuestionario están inscritos en el primer año, es decir, están iniciando estudiantes de secundaria con una edad promedio de 15 años (IFAP, 2019). 
Figura 09 Distribución de los estudiantes participantes según la edad.

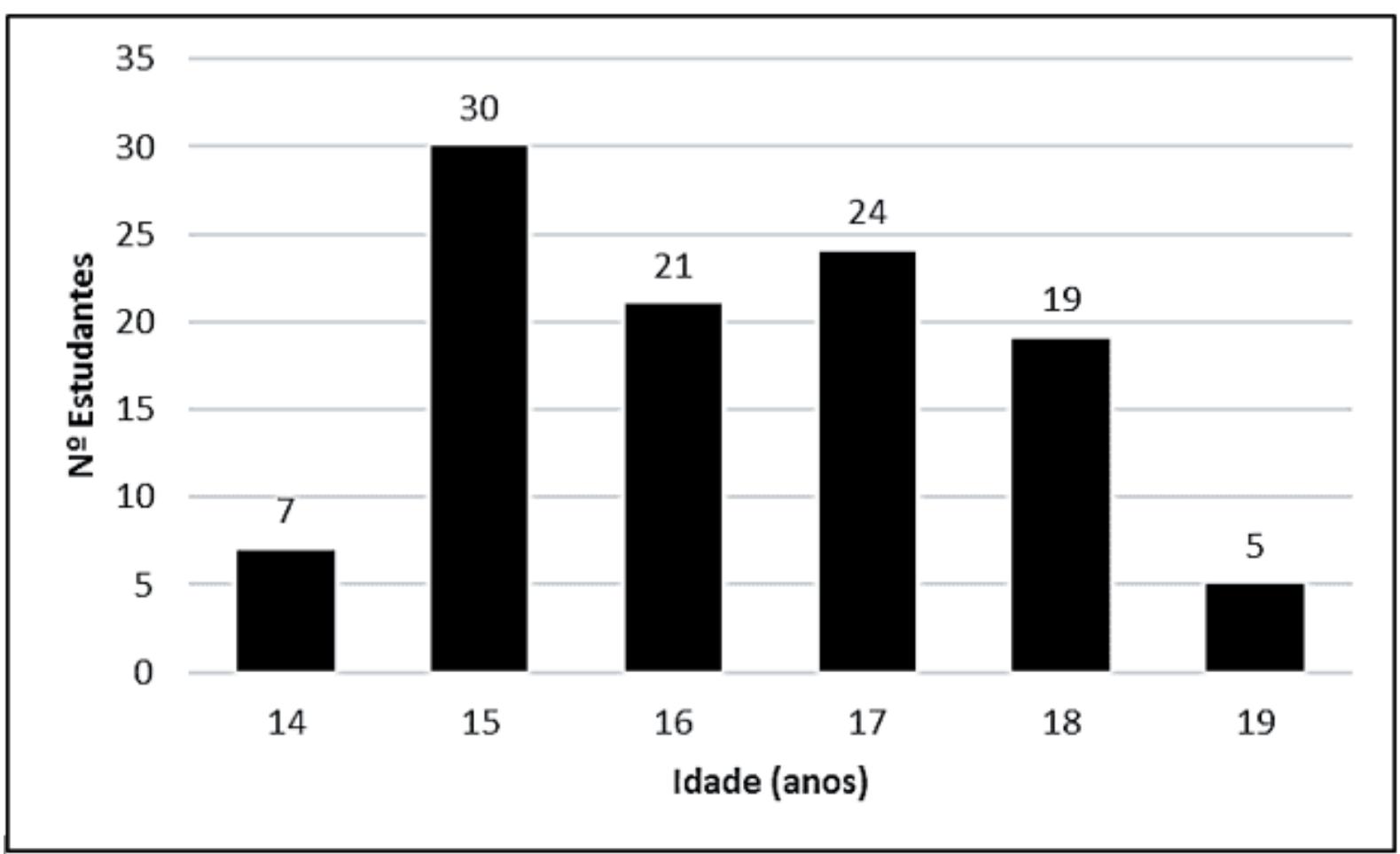

RC: 83560

Disponível em: https://www.nucleodoconhecimento.com.br/educacion-es/integradodel-instituto 
Figura 10 Distribución de los estudiantes participantes según grado/año.

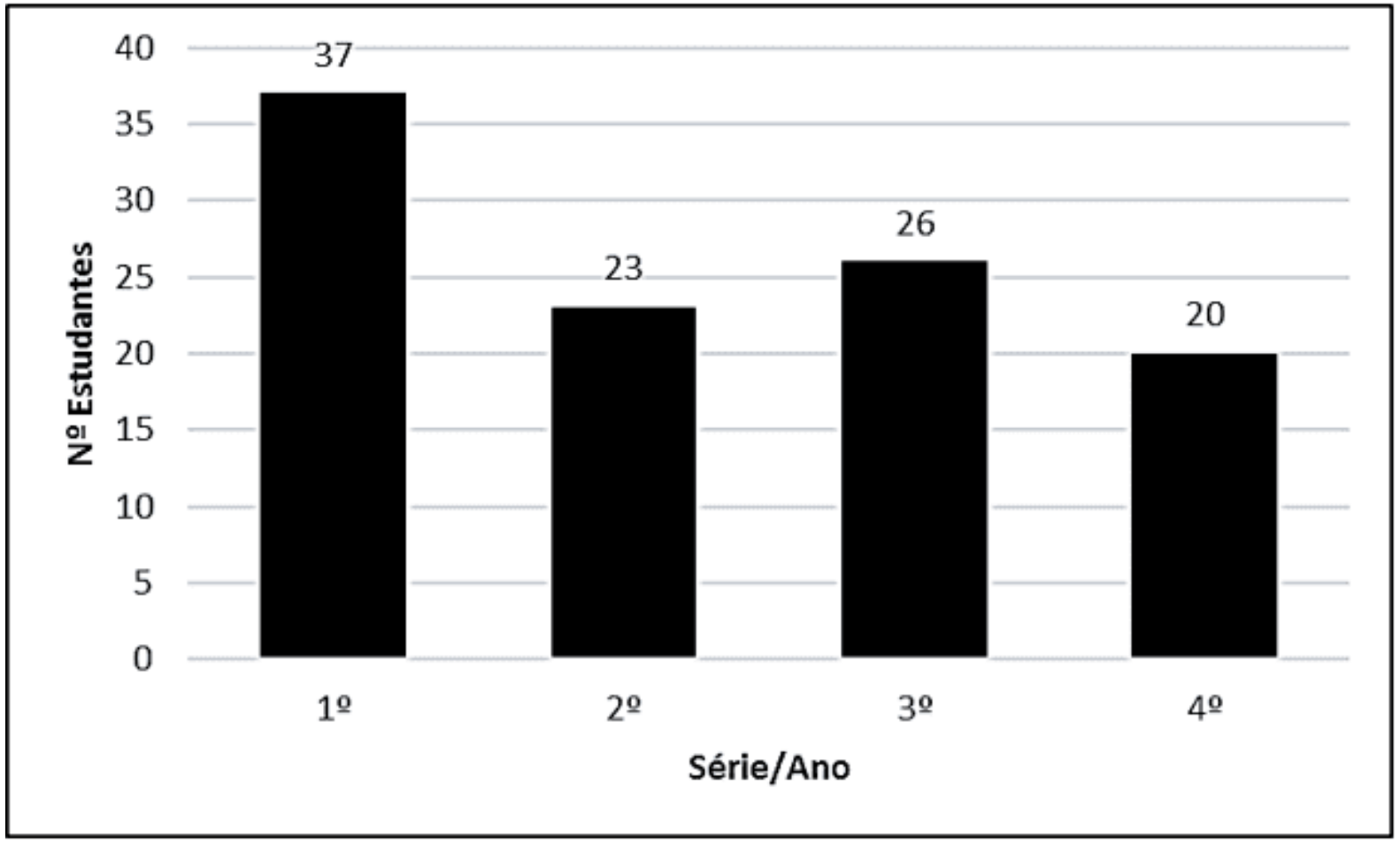

De los 106 estudiantes que participaron en la investigación, 56 son hombres y 50 son mujeres, lo que demuestra un equilibrio en relación con el género de los entrevistados, este resultado se puede evidenciar en la figura 11, donde estas cifras muestran que el $52,83 \%$ de los entrevistados son hombres y el $47,17 \%$ son mujeres (IBGE, 2010).

En cuanto a los ingresos familiares, la cifra 12 muestra que la mayoría del público entrevistado pertenece a la clase pobre. Este es el público de la escuela secundaria en forma integralizada de ifap, independientemente del campus o curso, reflejando de manera similar la pirámide de ingresos de Brasil (IBGE, 2021).

RC: 83560

Disponível em: https://www.nucleodoconhecimento.com.br/educacion-es/integradodel-instituto 
Figura 11 Distribución de los estudiantes participantes según género.

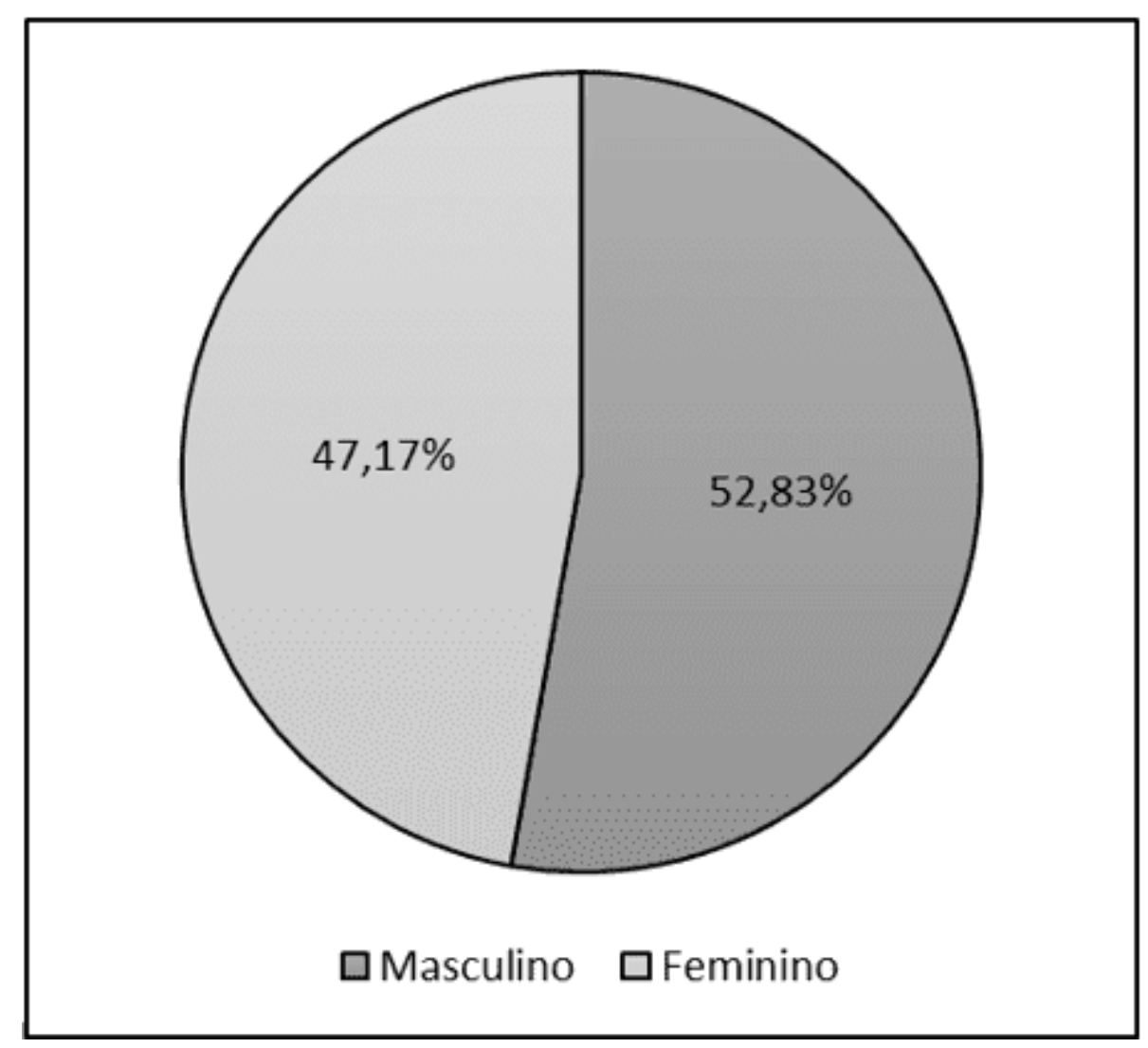

RC: 83560

Disponível em: https://www.nucleodoconhecimento.com.br/educacion-es/integradodel-instituto 
Figura 12 Distribución de los estudiantes participantes según los ingresos familiares.

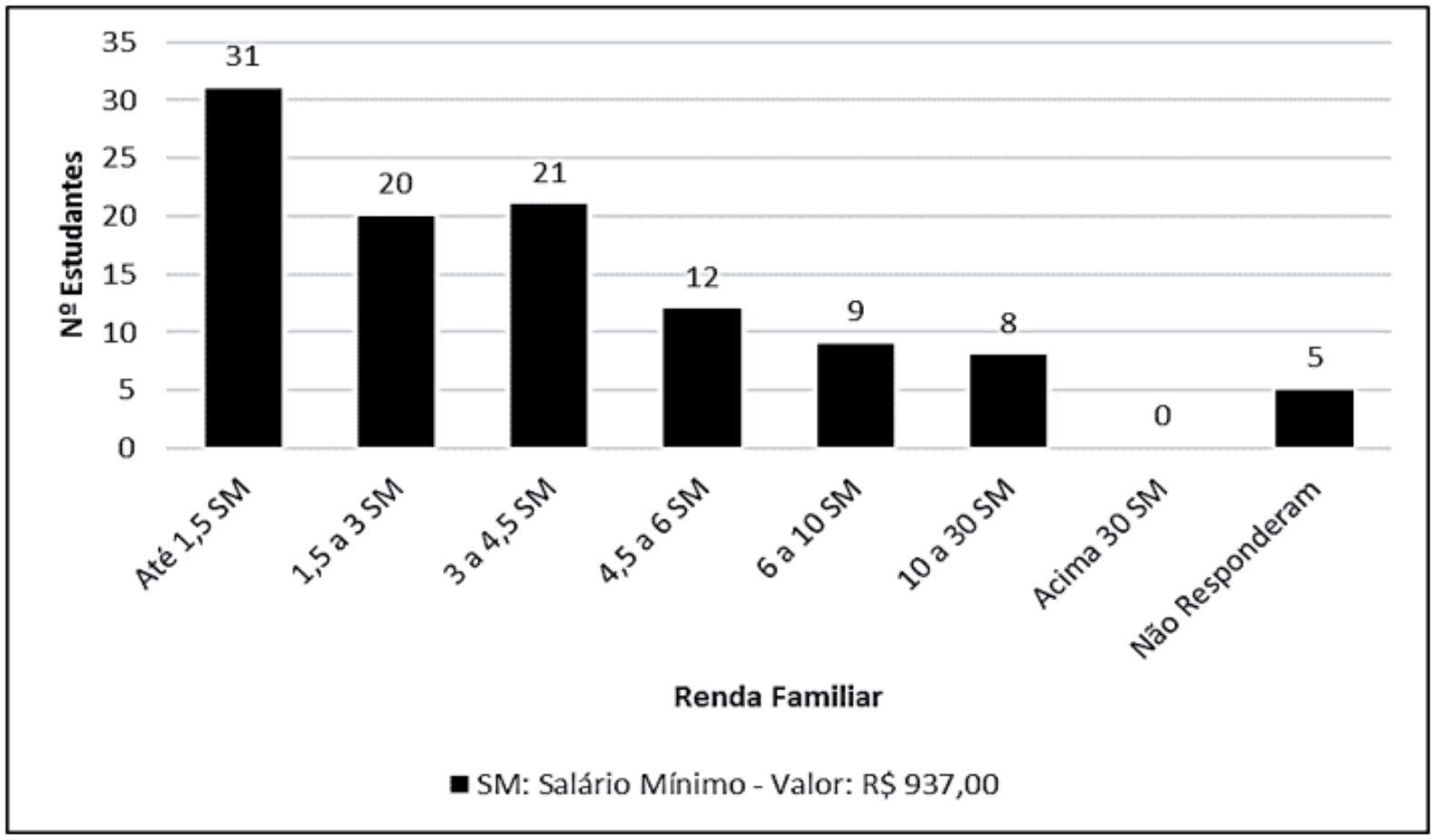

Se preguntó sobre la ubicación espacial de los tres poderes en Macapá. El conocimiento de la ubicación de las tres potencias en el espacio urbano es una prueba de su importancia social. El resultado mostró que el Ejecutivo es el más visible, seguido por la legislatura y finalmente el poder judicial, como se muestra en la figura 13 , donde el $44,65 \%$ de los entrevistados respondió correctamente a las preguntas sobre la notoriedad del Poder Ejecutivo. Este reflejo de la visibilidad social de los tres poderes se debe a una mayor inversión del Ejecutivo y la legislatura en los medios de comunicación que el poder judicial, principalmente porque sus ocupantes son elegidos por el pueblo, lo que hace que esta notoriedad sea cada vez más necesaria para su promoción personal, mientras que los ocupantes del poder judicial, en su mayoría, toman posesión a través de concurso público, es decir, se basan en el principio de meritocracia para ocupar el cargo y no requieren el voto popular (FIGUEIREDO, 2019). 
Figura 13 Visibilidad social de los tres poderes constituyentes en Macapá.

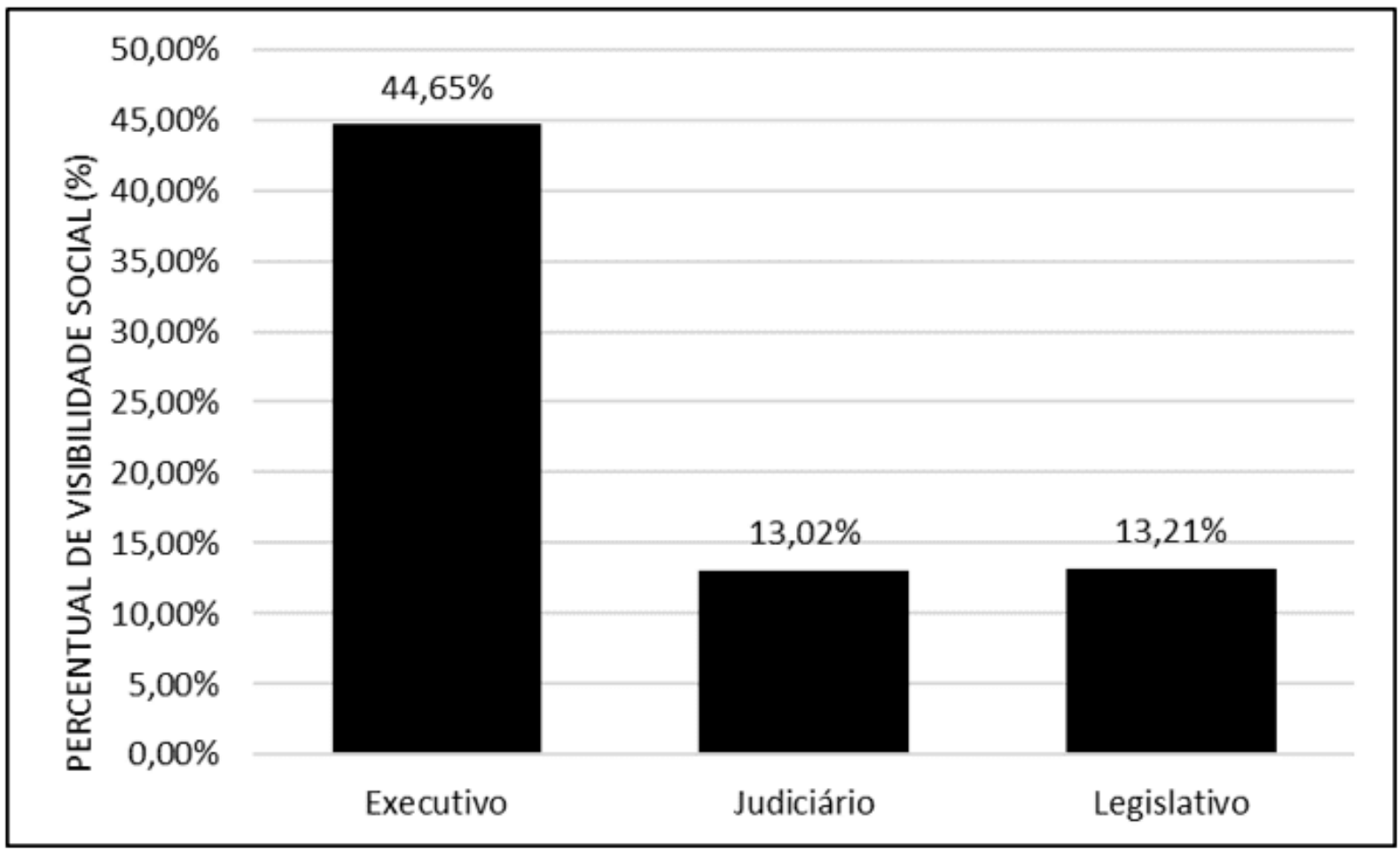

Las cuatro cifras siguientes (14 a 17) hacen una correlación entre la visibilidad social de las 3 potencias en Macapá y los factores que podrían influir en este índice de notoriedad. Entre los 4 factores encuestados, el que presentó una línea de tendencia más evidente fue el relacionado con la visibilidad social y la serie/año de los participantes, que se muestra en la Figura 15, donde se detectó que la visibilidad social de los 3 poderes aumenta a medida que los estudiantes pasan al siguiente grado.

RC: 83560

Disponível em: https://www.nucleodoconhecimento.com.br/educacion-es/integrado$\underline{\text { del-instituto }}$ 
Figura 14 Visibilidad social de los tres poderes constituyentes en Macapá según la edad.

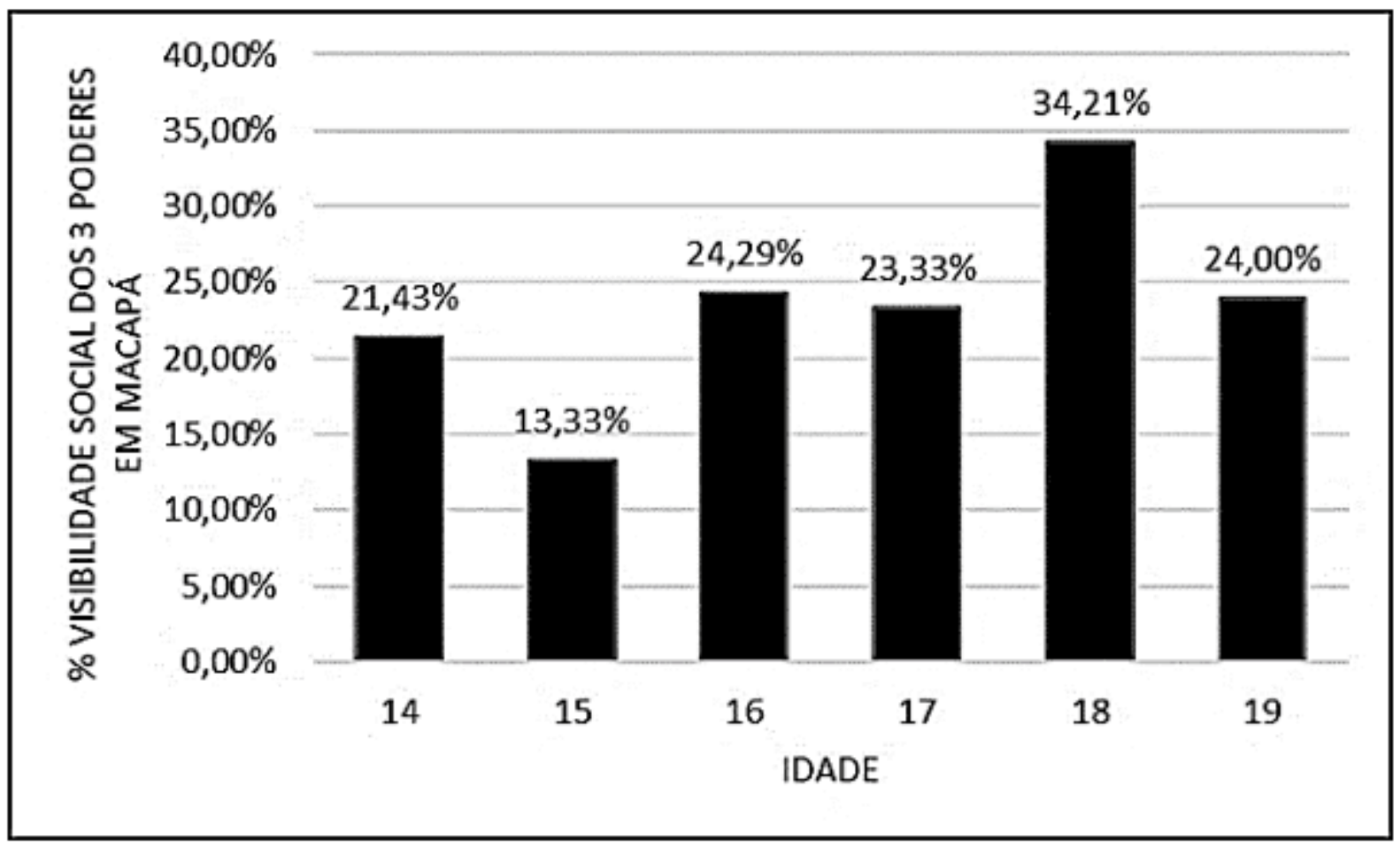

RC: 83560

Disponível em: https://www.nucleodoconhecimento.com.br/educacion-es/integradodel-instituto 
Figura 15 Visibilidad social de los tres poderes constituyentes en Macapá según la serie/año.

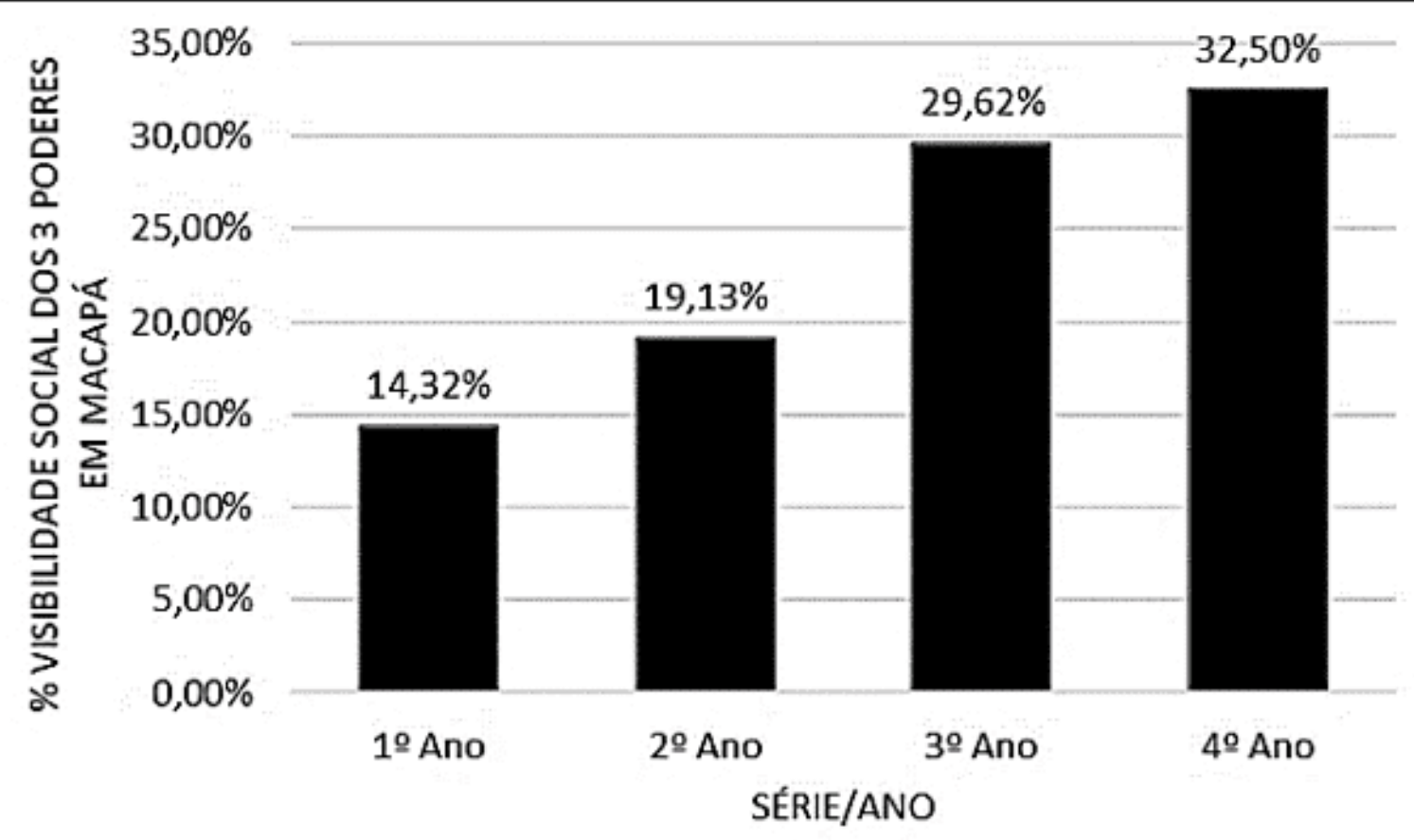

RC: 83560

Disponível em: https://www.nucleodoconhecimento.com.br/educacion-es/integradodel-instituto 
Figura 16 Visibilidad social de los tres poderes constituyentes en Macapá según la edad.

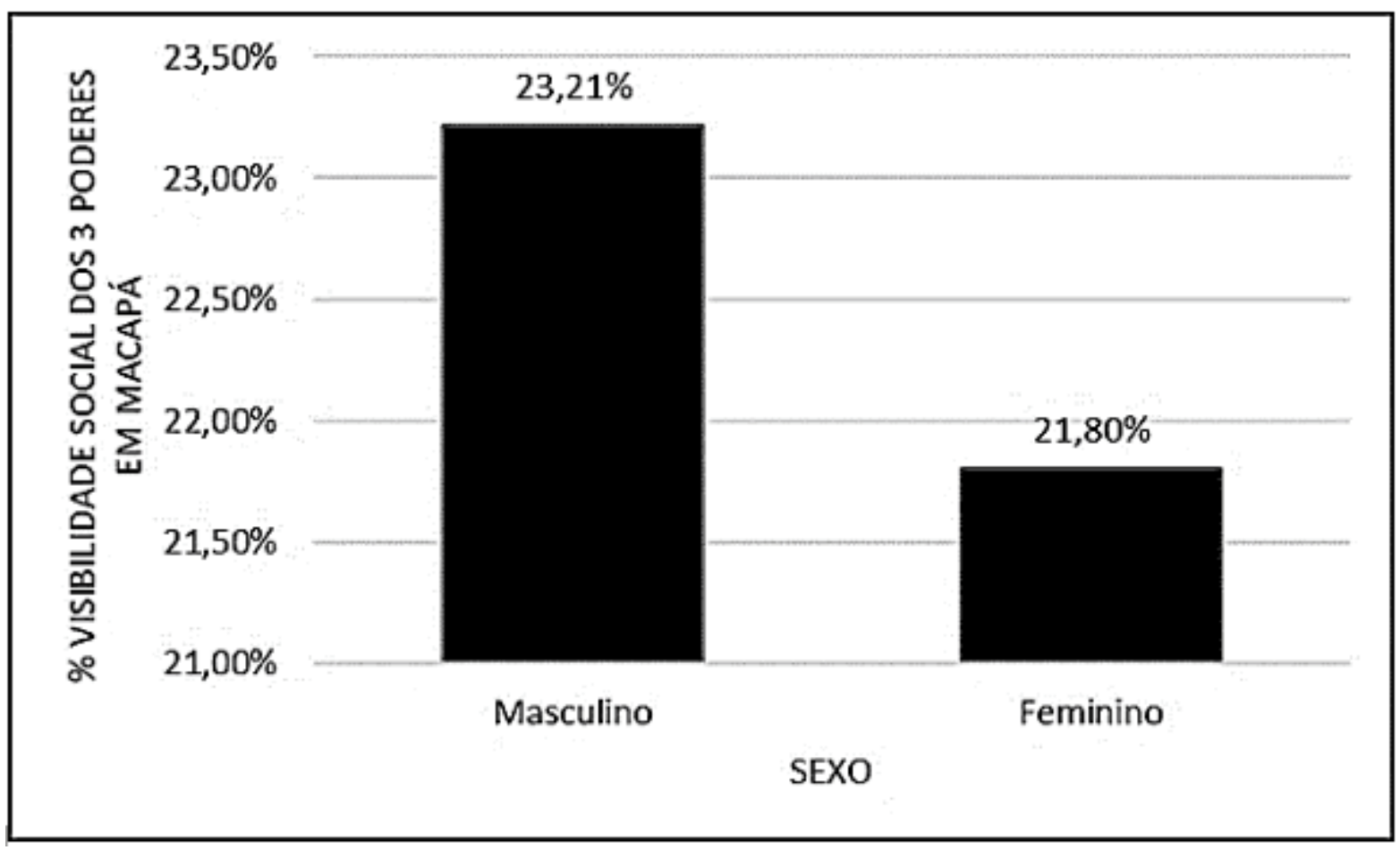

RC: 83560

Disponível em: https://www.nucleodoconhecimento.com.br/educacion-es/integradodel-instituto 
Figura 17 Visibilidad social de los tres poderes constituyentes en Macapá según la edad.

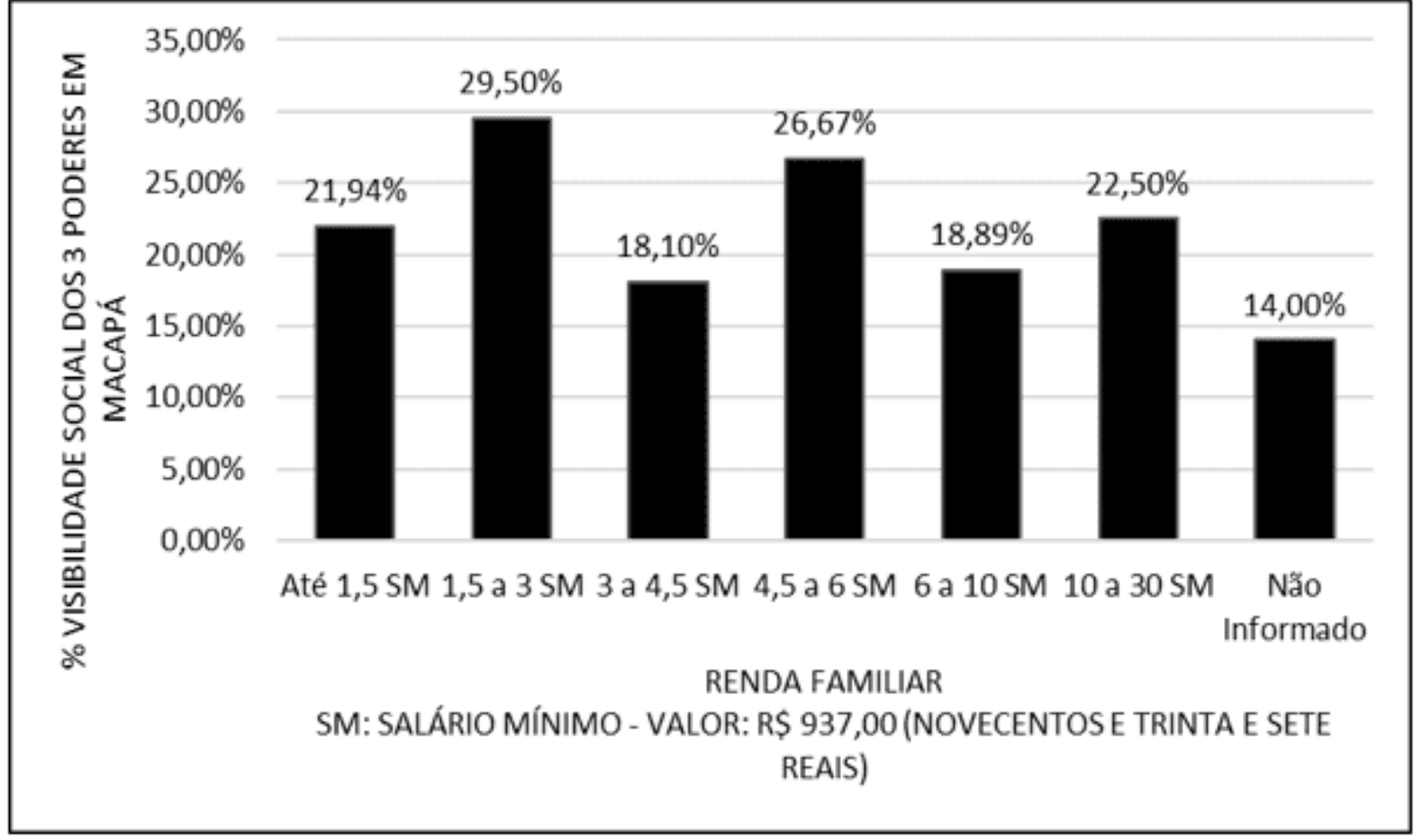

Este resultado puede deberse a los conocimientos adquiridos en la escuela, con la familia o ante la sociedad, que con la mayor interacción social que los estudiantes adquieren a lo largo de su vida, terminan asimilando una mayor cantidad de información sobre los poderes constituyentes (SILVA FILHO, 2004).

La Figura 18 muestra que el $49,01 \%$ de las respuestas elegidas por los entrevistados fueron erróneas, sin tener en cuenta el porcentaje del 5,38\% de las respuestas en blanco, que probablemente los participantes no sabían la respuesta correcta. Esto demuestra que el texto constitucional sigue siendo un bastión de los expertos y que la gran mayoría de los estudiantes probablemente ni siquiera manejó la Constitución Federal, lo que significa que no constituye la realidad de la escuela secundaria en la forma integralizada. No está trabajado, discutido por los estudiantes. Por lo tanto, es fácil suponer que ciertamente tampoco son conscientes de sus derechos y deberes básicos expresados allí. Si, cuando completan la escuela

RC: 83560

Disponível em: https://www.nucleodoconhecimento.com.br/educacion-es/integradodel-instituto 
secundaria, no dominan ese conocimiento, queda por creer que vendrán a lo largo de su vida ciudadana, en ocasiones de conflicto, o en otras más leves, si vienen, cuando un evento afecta a su libertad o propiedad (DIAS y DE OLIVEIRA, 2015).

Figura 18: Resultado de las preguntas sobre fundamentos de la Constitución Federal.

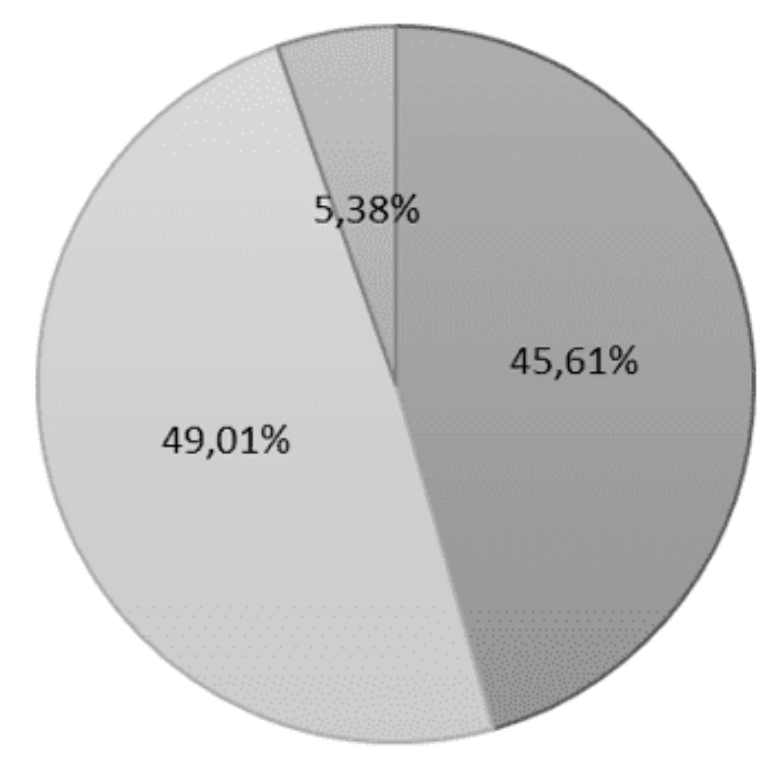

$\square$ Acertos $\quad \square \%$ Erros $\quad \square \%$ Não Responderam

Las figuras 19, 20, 21 y 22 a continuación muestran los resultados de las preguntas en la sección de Fundamentos de la Constitución Federal en relación con factores de edad, grado/año, sexo e ingresos familiares, respectivamente. En estos resultados, encontramos el porcentaje de respuestas correctas en relación con las respuestas de las preguntas sobre el hijo básico de CF de acuerdo con los criterios investigados. 
Figura 19 Porcentaje de respuestas correctas sobre los conceptos básicos del CF según la edad.

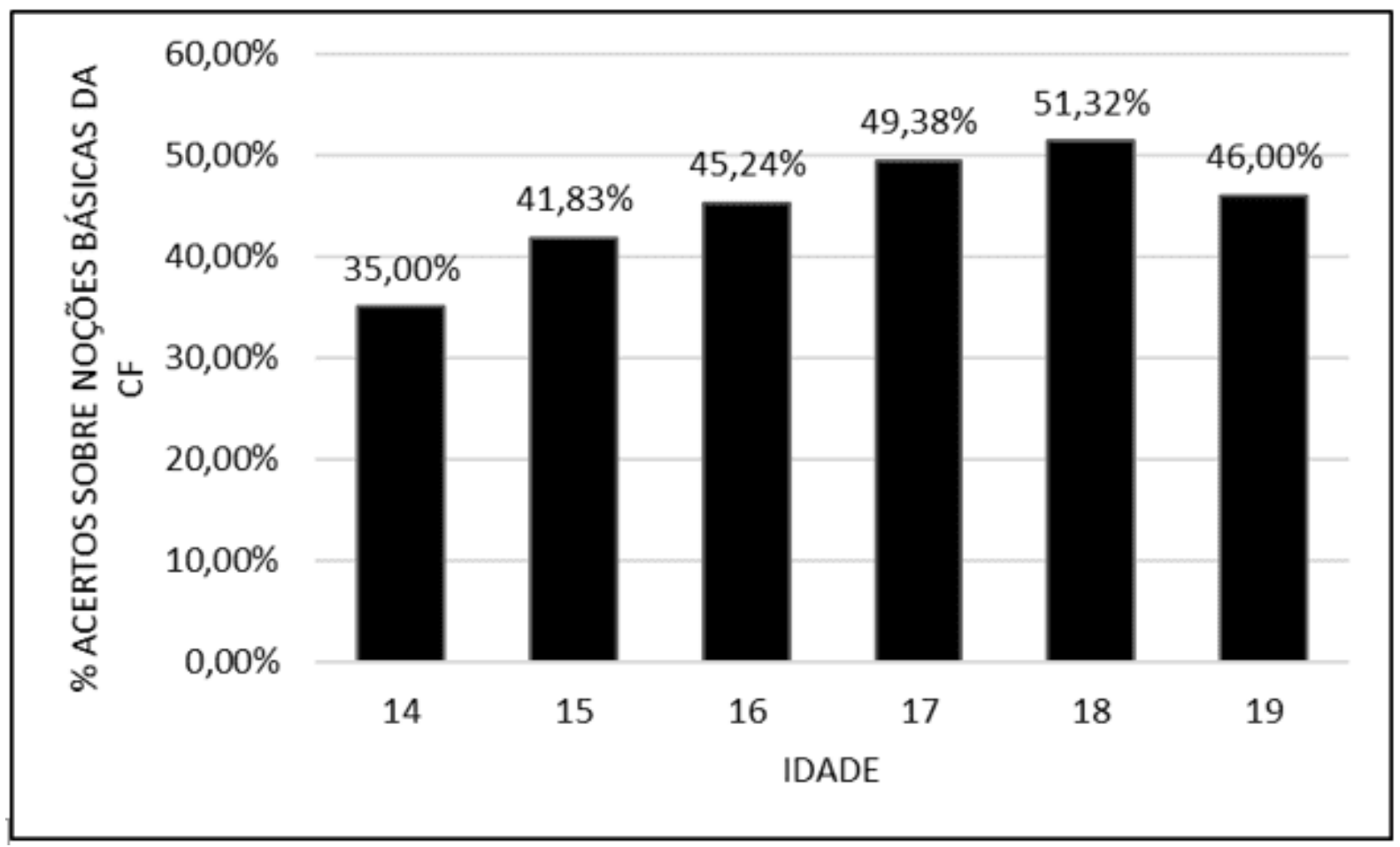

RC: 83560

Disponível em: https://www.nucleodoconhecimento.com.br/educacion-es/integradodel-instituto 
Figura 20 Porcentaje de respuestas correctas sobre los conceptos básicos del CF según la serie/año.

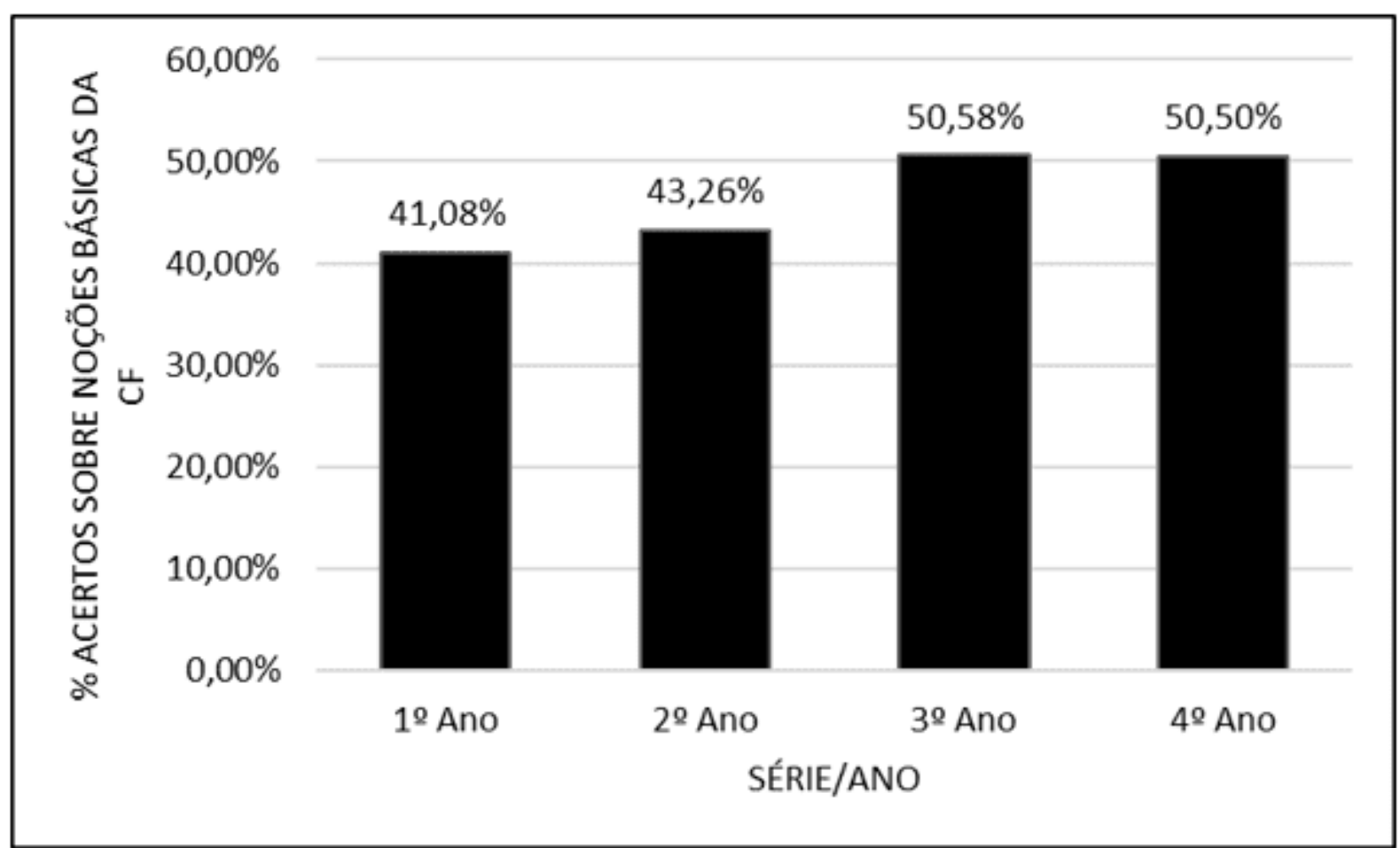

RC: 83560

Disponível em: https://www.nucleodoconhecimento.com.br/educacion-es/integradodel-instituto 
Figura 21 Porcentaje de respuestas correctas sobre los fundamentos del CF según el género.

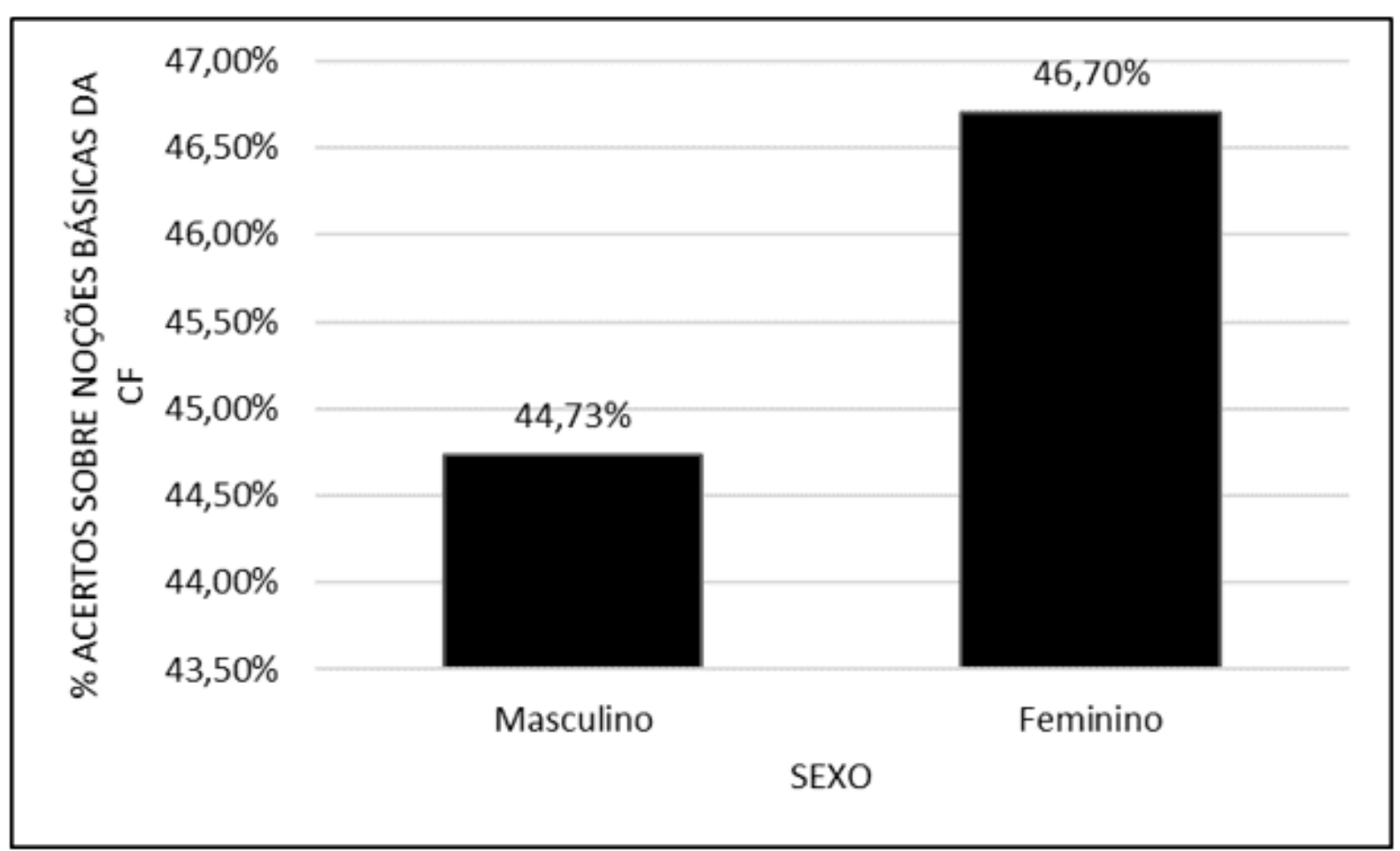

RC: 83560

Disponível em: https://www.nucleodoconhecimento.com.br/educacion-es/integradodel-instituto 
Figura 22 Porcentaje de respuestas correctas sobre los fundamentos del CF según los ingresos familiares.

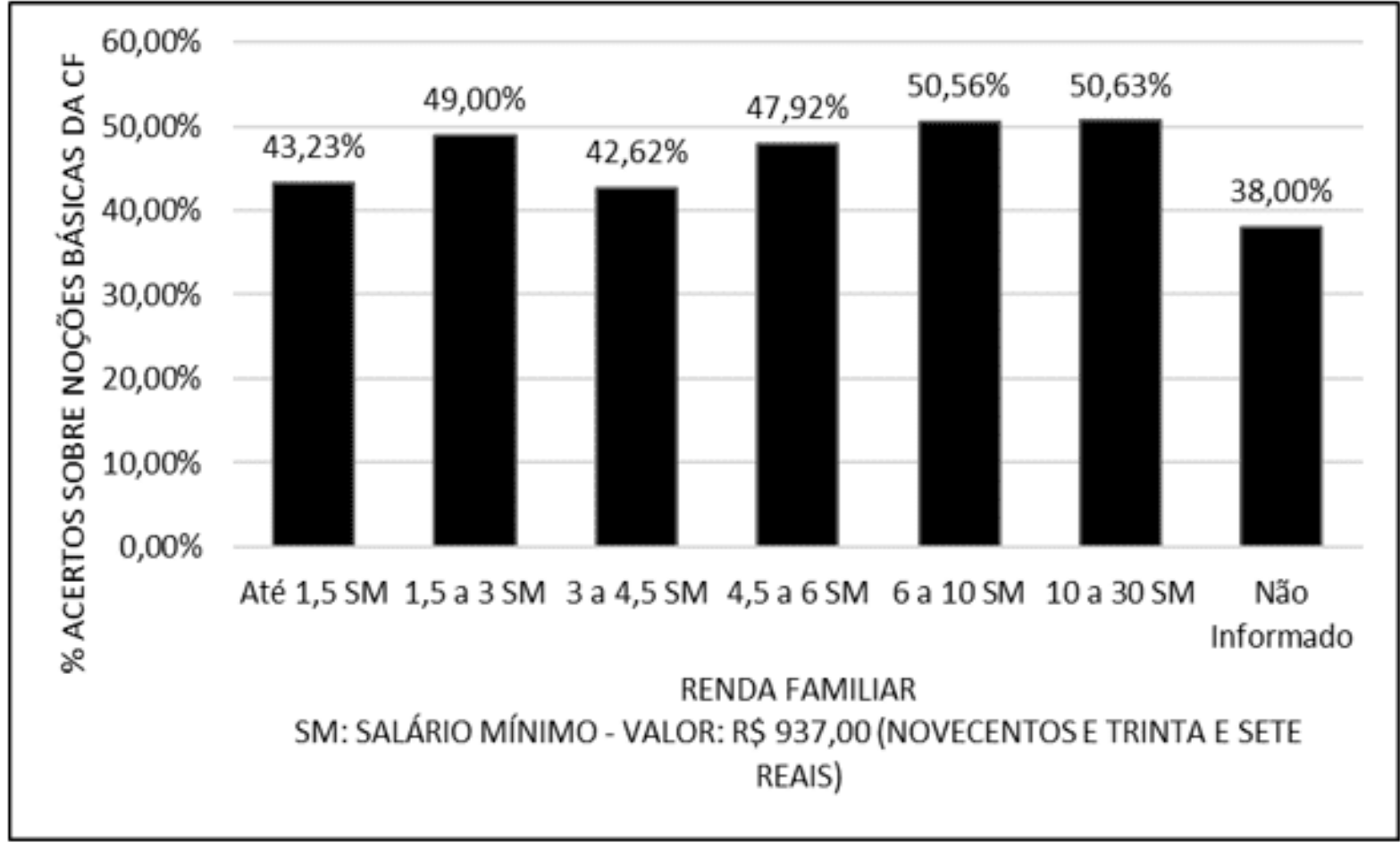

Aunque los gráficos de las figuras 19 y 20 presentan algunas distorsiones en sus líneas de tendencia, podemos notar un mayor porcentaje de respuestas correctas a medida que los estudiantes avanzan al siguiente grado y, en consecuencia, tienen una edad más alta, esto es el resultado de una interacción social ma.ior por parte de los encuestados. La distorsión de las dos últimas columnas de los dos gráficos antes mencionados probablemente refleja la incapacidad de estos estudiantes con el cuestionario o porque en su mayoría son estudiantes repetidos que no muestran interés en el proceso de enseñanza y aprendizaje de la institución (ALMEIDA y ALVES, 2021).

También podemos observar en la Figura 21 un equilibrio en las respuestas correctas de los entrevistados masculinos y femeninos, lo que refleja que este factor no interfiere directamente en los resultados obtenidos. En cuanto a la figura 22, encontramos una ligera tendencia de los encuestados con mayores ingresos

RC: 83560

Disponível em: https://www.nucleodoconhecimento.com.br/educacion-es/integradodel-instituto 
familiares a presentar una tasa más alta de respuestas correctas, pero esta influencia no es muy significativa y se puede cuestionar fácilmente (FERREIRA y LEISMANN, 2020)

El resultado de la Figura 23 muestra que la mayoría de los entrevistados demuestran que tienen principios de justicia y filosofía que son esenciales para la interacción social, no presentando contradicciones en sus principios, aunque detectamos algunas respuestas contradictorias y en blanco de algunos entrevistados.

Figura 23 Porcentaje de estudiantes que demuestran tener algún principio de justicia y filosofía. Figura 24 Porcentaje de estudiantes que respondieron a las respuestas con influencia de su vida social.

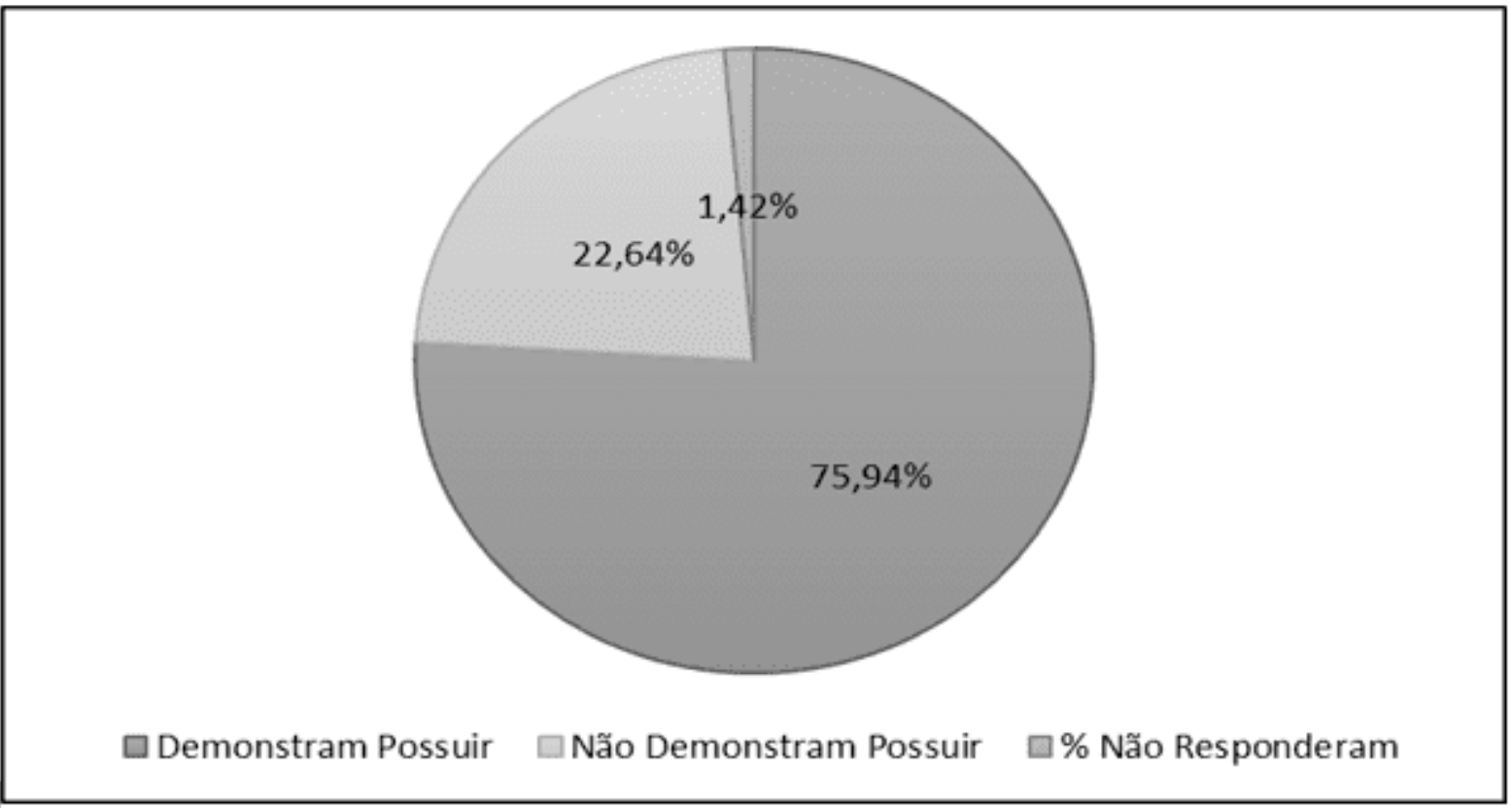

RC: 83560

Disponível em: https://www.nucleodoconhecimento.com.br/educacion-es/integradodel-instituto 
La Figura 24 muestra que pocos estudiantes tienen la intención de asistir a la ley, esto ya se esperaba, ya que los entrevistados asisten a edificaciones, curso en el área exacta, lo que refleja que la intención de asistir a la ley no influyó significativamente en las respuestas obtenidas.

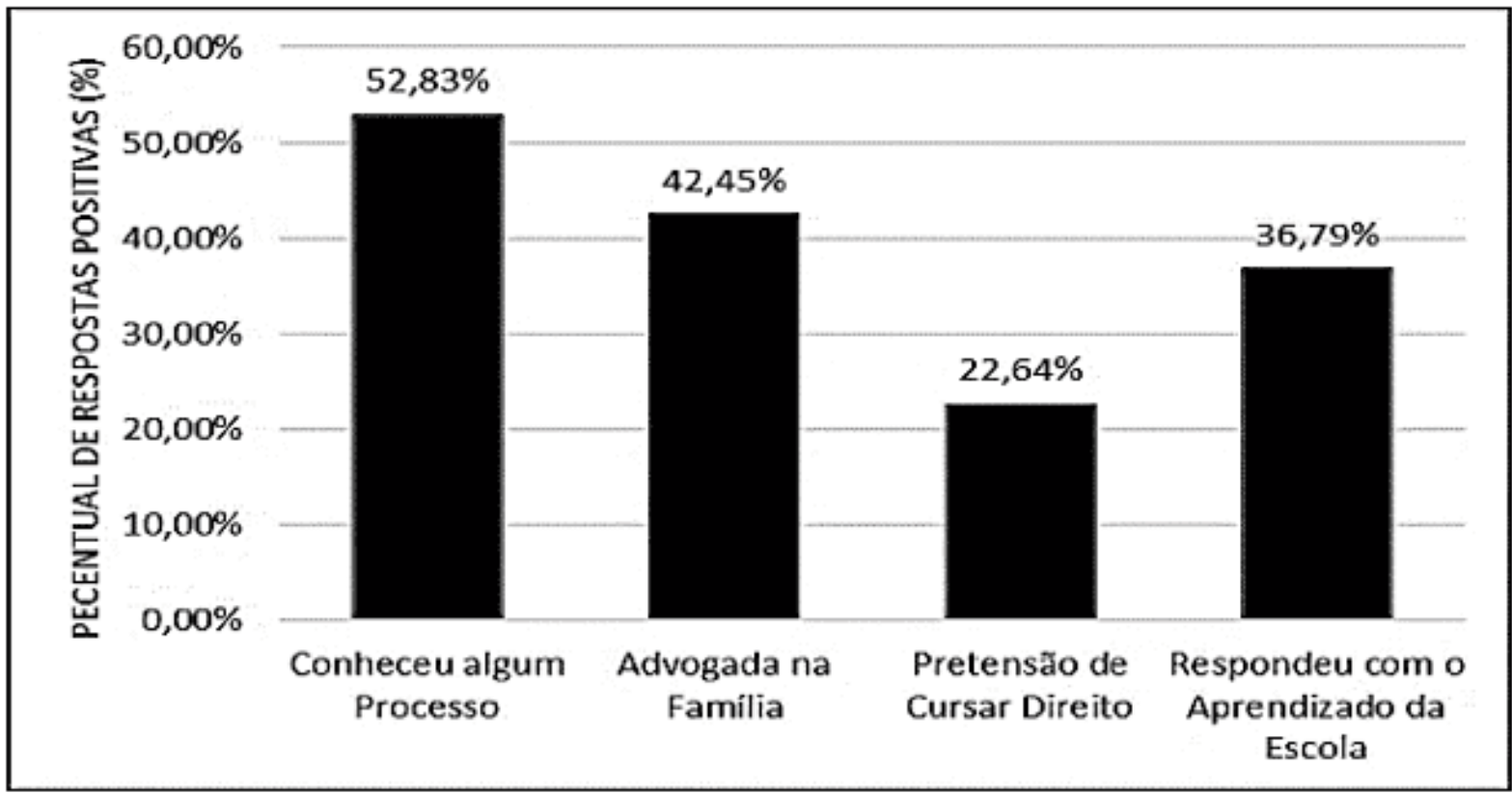

Por otro lado, mostramos que el $52,83 \%$ de los entrevistados ya han sido testigos de un proceso judicial en algún momento de su vida, lo que puede haber contribuido a sus respuestas, esto es una advertencia a la sociedad, porque cada vez es más esencial que los ciudadanos tengan conocimientos básicos de derecho, ya que necesitarán este conocimiento en su vida cotidiana (LOTTERMANN et al. , 2020).

El punto negativo es que pocos estudiantes confirmaron que respondieron a las preguntas del cuestionario con lo que aprendieron en la escuela, demostrando un fracaso en la enseñanza, ya que la función social de la escuela es la propagación y democratización de los conocimientos necesarios para la formación de ciudadanos conscientes, participativos y activos en la sociedad, y tener como principios y objetivos de la República Federativa de Brasil en la construcción de una sociedad libre , justo y solidario (LOTTERMANN et al., 2020).

Disponível em: https://www.nucleodoconhecimento.com.br/educacion-es/integradodel-instituto 
Aunque la Figura 25 muestra que sólo el $35,85 \%$ de los estudiantes entrevistados hicieron algún comentario, todos los comentarios escritos en esta sección, en general, fueron positivos. Entre los comentarios de los estudiantes había una homogeneidad de género y para las clases más avanzadas, siempre obtuvimos un menor número de comentarios.

Figura 25 Porcentaje de estudiantes que comentaron sobre el cuestionario.

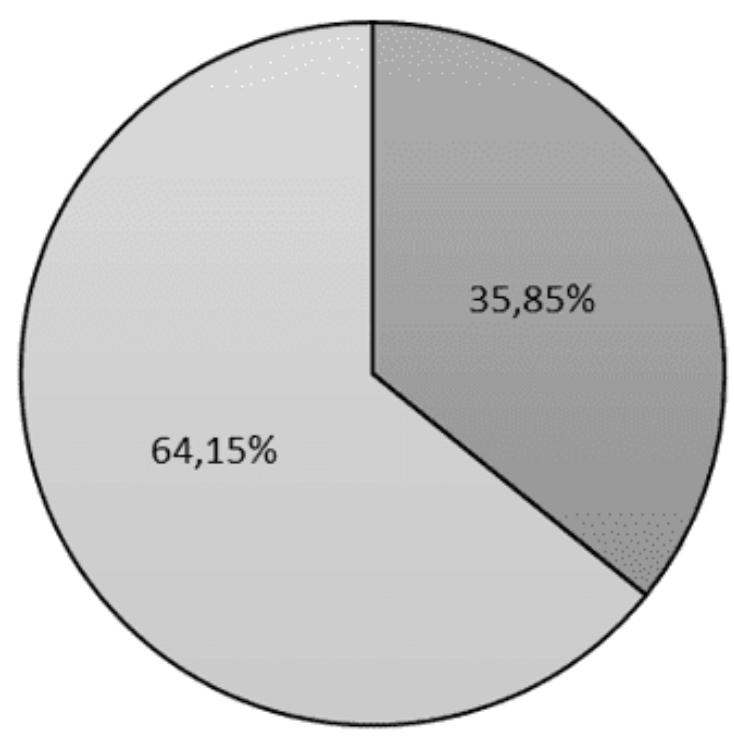

$\square \%$ Comentários $\quad \square \%$ Sem Comentários

La mayoría de los comentarios registrados informaron que el cuestionario era muy interesante y bien elaborado, corroborando la relevancia del estudio del CF en las escuelas. También detectamos que algunos estudiantes se despertaron ante la falta de conocimiento sobre el tema, informando que nunca aprendieron esto en la escuela (MORAES, 2013).

Tuvimos algunos comentarios inesperados, como el hecho de que un estudiante no residía en el municipio de Macapá, obstaculizando sus respuestas sobre la ubicación espacial de los poderes. Otro comentario indicó que el cuestionario despertó el mayor aprecio del estudiante por el curso de derecho, al que pretende ingresar, por 
no hablar de los juegos, típicos de los estudiantes de este grupo de edad, utilizando palabras como: "Guay", diez, etc., para describir el cuestionario.

\section{CONCLUSIONES}

A pesar de los diferentes proyectos llevados a cabo hasta ahora en relación con la implementación de la ley en las escuelas básicas, este esfuerzo aún no ha logrado llegar a toda la nación brasileña, pero es un esfuerzo para ser practicado con responsabilidad y esperanza en el camino hacia una transformación social

La buena voluntad de la mayoría de las materias involucradas en el cambio de la realidad brasileña se percibió enseñando una disciplina de vital importancia. Esto se verificó en los resultados de los cuestionarios, creyendo que su propia solicitud era bastante saludable, porque despertó debates y dudas entre los involucrados, lo que terminó, de alguna manera, calificando a los participantes

La Preparatoria Brasileña, examinada a partir de un corte puntual en el curso técnico en edificios en forma integralizada del IFAP, campus Macapá, no puede cumplir con las recomendaciones del CF y el LDB de acuerdo con el resultado del cuestionario aplicado a los estudiantes. Esta Enseñanza ocupa un lugar privilegiado en la educación brasileña, entre la primaria y la

Los estudiantes muestran estar entusiasmados con la posibilidad de implementar escaneos básicos en el curso técnico en edificios del IFAP, campus Macapá, aunque opcionalmente.

\section{REFERENCIAS}

ALMEIDA, F. A.; ALVES, M. T. G. A cultura da reprovação em escolas organizadas por ciclos. Revista Brasileira de Educação, v. 26, p. 1-28, 2021. 
AMARAL, D. P. D.; CASTRO, M. M. D. Educação moral e cívica: A retomada da obrigatoriedade pela agenda conservadora. Cad. Pesqui., v. 50, n. 178, p. 10781096, 2020.

ANTONELLO, I. P.; NOREMBERG, A. DIREITO E EDUCAÇÃO: a promoção da cidadania nas escolas brasileiras utilizando-se da disciplina de direito constitucional. XII Seminário De Demandas Sociais E Políticas Públicas $\mathrm{Na}$ Sociedade Contemporânea. Santa Cruz do Sul RS: UNISC 2016.

BRASIL. LEI № 8.112, DE 11 DE DEZEMBRO DE 1990. Brasilia DF, 1990. Disponível em: < http://www.planalto.gov.br/ccivil_03/leis//8112cons.htm >. Acesso em: 17 mar 2021.

. Constituição da República Federativa do Brasil (1988). DEPUTADOS, C.

D. Brasília DF: Edições Câmara 2012.

. LDB: Lei de diretrizes e bases da educação nacional - Lei no 9.394, de 20 de dezembro de 1996. Brasília DF: Edições Câmara 2016.

. Novo Ensino Médio - DÚVIDAS. MEC. Brasilia DF: MEC 2017.

DIAS, L. S.; DE OLIVEIRA, L. B. Acesso à educação jurídica: pela inclusão do ensino jurídico na grade curricular do ensino regular. Rio de Janeiro RJ, 2015. Disponível em:

https://periodicos.ufrn.br/constituicaoegarantiadedireitos/article/viewFile/8159/5897 >. Acesso em: 13 jun. 2017.

FERREIRA, T. A.; LEISMANN, E. L. Lei anticorrupção: Conhecimento e percepção na academia a partir de diferentes condições socioeconômicas. Administração de Empresas em Revistas v. 2, n. 21, p. 216-234, 2020. 
FIGUEIREDO, C. B. D. As Funções Do Estado: O Princípio Da Separação De Poderes. XVIII Jornada e Mostra de Estudos Jurídicos e Sociais. Santa Rosa RS: Faculdades Integradas Machado De Assis: 44-48 p. 2019.

FONSECA, C. J. D.; FERNANDES, L. F. A importância do conhecimento contábil matemático para a ciência jurídica: Uma revisão integrativa. J Business Techn, v. 17, n. 3, p. 116-135, 2020.

HOHENDORFF, R. V. et al. "Você Sabia? O Direito te Desafia!": Relato de Caso do Uso de Jogo de Tabuleiro com Cartas para Demonstrar a Alunos de Ensino Médio o Quanto o Direito pode ser Instigante. Anais do V Congresso sobre Tecnologias na Educação (Ctrl+E 2020). João Pessoa PB 2020.

IBGE. População - Distribuição da população por sexo. Brasilia DF, 2010. Disponível em: < https://brasilemsintese.ibge.gov.br/populacao/distribuicao-dapopulacao-por-sexo.html >. Acesso em: 17 mar 2021.

. Contas nacionais - PIB per capita. Brasilia DF, 2021. Disponível em: < https://brasilemsintese.ibge.gov.br/contas-nacionais/pib-per-capita.html >. Acesso em: 17 mar 2021.

IFAP. Resolução no 67.2019 Consup. Macapa AP: IFAP 2019.

Histórico. Macapa AP, 2021. Disponível em: < https://www.ifap.edu.br/index.php/quem-somos/historico >. Acesso em: 17 mar 2021.

LORENSET, R. B. C. et al. Direito e linguagem se (entre)laçam e se (con)fundem. Anuário Pesquisa e Extensão Unoesc Xanxerê, v. 6, p. 1-6, 2021.

LOTTERMANN, O.; SIQUEIRA, E.; CESARO, I. A. D. Mediações Do Conhecimento Escolar De Ensino Médio Com O Conhecimento Científico, O Mundo Do Trabalho E O Exercício Da Cidadania. Contexto \& Educação, n. 112, p. 200-216, 2020. 
MORAES, E. D. F. R. M. A importância da introdução de disciplinas jurídicas no ensino médio. Magistro, v. 8, n. 2, p. 27-45, 2013. Disponível em: < http://publicacoes.unigranrio.edu.br/index.php/magistro/article/view/2119/997 >.

NÓBREGA, V. V. D.; CORRÊA, C. S.; JESUS, J. C. D. Diferenciais De Gênero No Mercado De Trabalho Brasileiro Em 2016 E 2017. Campinas, SP, 2019. Disponível em: < https://abep.org.br/publicacoes/index.php/anais/article/viewFile/3556/3407 >. Acesso em: 17 mar 2021.

ROMARIO. Projetos de Lei. Brasilia DF, 2021. Disponível em: < https://romario.org/projetos/lei/ >. Acesso em: 17 mar 2021.

SARAIVA. Vade Mecum. 11. São Paulo SP: Saraiva, 2017.

SASSE, C. Pesquisa DataSenado mostra que poucos conhecem realmente a Constituição. 2013.

Disponível em:

http://www12.senado.leg.br/noticias/materias/2013/10/25/pesquisa-datasenadomostra-que-poucos-conhecem-realmente-a-constituicao-do-pais >. Acesso em: 4 out. 2017.

SILVA FILHO, N. A. Projeto OAB Vai à Escola continua se expandindo. São Paulo SP, 2004. Disponível em: < http://www.oabsp.org.br/noticias/2004/05/18/2413 >. Acesso em: 22 nov. 2017.

TAVARES, T. P.; MOTA, M. F.; FELDENS, D. G. O Ensino Moral E Cívico Como Princípios Educativos Na Formação Dos Cidadãos. Interfaces Científicas v. 8, n. 3, p. 422-433, 2020.

Enviado: abril de 2021.

Aprobado: abril de 2021. 